\title{
Finding the Correct Pesticide Applicator License in Florida ${ }^{1}$
}

\author{
Erin E. Harlow, Luke B. Harlow, Susan Haddock, and Brett W. Bultemeier ${ }^{2}$
}

The Florida Department of Agriculture and Consumer Services oversees the licensing of all pesticide applicators in the state of Florida. It can be difficult knowing which of the 13 licenses with over 20 categories is needed, but having the correct license is important. The goal of this document is to assist with selecting the correct license and increase understanding of how best to prepare for obtaining and maintaining that license.

To use the "Florida Pesticide License Dichotomous Key" below, simply answer the questions until you are directed to your pesticide license page. Once there you will find all the information about study material, license cost, timelines, and renewal process. If you already know your license, you can find it from the list at the end of this document. This document is intended for UF/IFAS Extension personnel or the public to help identify the proper license for pesticide applications.

Key terms to know before using this document:

\section{Florida Department of Agriculture and Consumer} Services (FDACS) - The state entity that regulates Florida pesticide licenses.
Restricted Use Pesticide (RUP) - Pesticide products in this category are limited for sale and use by licensed applicators only. A product that is RUP will be marked as such on the first page of the pesticide label.

Public-Refers to an employee of the government, or a public entity. Examples could include schools, counties, universities, public works departments, etc. Your paycheck is signed by a "public" employer.

Commercial-Refers to a person that is "for hire." Applications are done at locations that pay you (or your employer) for the work that is done.

Private-Refers to a person who works on property that they own or lease, or works exclusively on the property of their employer.

Continuing Education Units (CEUs) - Training approved by the Florida Department of Agriculture and Consumer Services (FDACS) for recertification of licenses. One CEU $=50$ minutes of active learning.

487 A License Might Not Be Needed-If using a General Use Pesticide (GUP), which is any product that does not have RUP labeling on the top of the product, then a license

1. This document is PI292, one of a series of the Pesticide Information Office, UF/IFAS Extension. Original publication date August 2021. Revised September 2022. Visit the EDIS website at https://edis.ifas.ufl.edu for the currently supported version of this publication.

2. Erin E. Harlow, residential and commercial horticulture agent III, UF/IFAS Extension Columbia County; Luke B. Harlow, agriculture and natural resources agent I, UF/IFAS Extension Union County; Susan Haddock, commercial horticulture integrated pest management agent IV, UF/IFAS Extension Hillsborough County; and Brett Bultemeier, Extension assistant professor, UF/IFAS Pesticide Information Office, Gainesville, FL 32653; UF/ IFAS Extension, Gainesville, FL 32611.

Use pesticides safely. Read and follow directions on the manufacturer's label.

The Institute of Food and Agricultural Sciences (IFAS) is an Equal Opportunity Institution authorized to provide research, educational information and other services

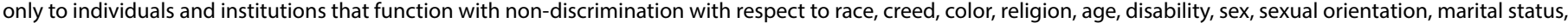

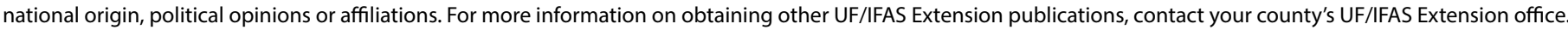
U.S. Department of Agriculture, UF/IFAS Extension Service, University of Florida, IFAS, Florida A \& M University Cooperative Extension Program, and Boards of County Commissioners Cooperating. Nick T. Place, dean for UF/IFAS Extension. 
is not always required. However, it is always suggested to hold the appropriate license for your category. If you still want to know what license is needed, follow the dichotomous key as if you are using RUP products, even if you are not.

487 Categories-Any category that lists the category + CORE requires the CORE exam be passed in addition to the category exam. Those wishing to add categories beyond the original category do not have to retake the CORE exam and do not have to pay for a separate license. There is no limit to the number of categories that can be added to the original 487 license. 
Florida Pesticide License Dichotomous Key

Do you apply products to:

1. Mosquitos and other public health threats, CH 388 F.S.

a. Yes-go to Table 1.1.

b. No-go to 2 .

2. The interior or exterior of occupied buildings, CH 482 F.S.

a. Yes-go to Table 2.1.

b. No-go to 3 .

3. Agriculture and all other sites, CH 487 F.S.

a. Yes-go to Table 3.1.

Table 1.1. Mosquitos and other public health threats.

1. Do you work for the government or on government property?

a. Yes-Public Health. Go to page 6.

b. No-go to 2 .

2. Do you install and service automated mosquito misting devices and/or offer residential or commercial fogging and barrier treatments around occupied structures (homes, hotels, resorts, etc.)?

a. Yes-Pest Control Operator in General Household Pests (GHP) or Lawn and Ornamental (L\&O). Go to pages 16 or 24.

b. No-go to 3.

3. Do you make mosquito-control applications to private, commercial, or governmental properties that do not include buildings, and are you for hire?

a. Yes-Public Health. Go to page 6.

b. No-go to 4.

4. Are you or do you plan to be a director of a county or district mosquito control program? a. Yes-Mosquito Control Directors. Go to page 8.

Table 2.1. The interior or outside of occupied buildings, CH 482 F.S.

1. Do you work for the government or on private property and are not a contractor?

a. Yes-go to Table 2.2.

b. No-go to 2 .

2. Are you a for-hire contractor?

a. Yes-go to Table 2.3.

Table 2.2. Government or private property around occupied buildings.

1. Do you treat household pests and rodents in and around structures?

a. Yes-Limited Structural. Go to page 10.

b. No-go to 2.

2. Do you treat lawns and ornamentals around buildings?

a. Yes-Limited Lawn and Ornamental, unless using Ready-to-Use product, then no license. Go to page 12.

b. No-go to 3.

3. Are you a volunteer?

a. Yes-no license or Limited Lawn and Ornamental if product requires it.

Table 2.3. For-hire contractors around occupied buildings. CH 482, F.S.

Do you:

1. Trap rodents around and in buildings. No bait is allowed_Limited Wildlife. Go to page 14.

2. Trap or treat household pests and rodents in and around buildings-General Household Pest (PCO GHP) or ID Cardholder. Go to page 16 or 30.

3. Treat or inspect for termites and other wood destroying organisms in and around structures, including landscapes-Wood-Destroying Organism (PCO WDO) or ID Cardholder/Special ID Cardholder. Go to page 18 or 30/22.

4. Fumigate structures for wood-destroying organisms-Structural Fumigation (PCO FUM) or Special ID Cardholder. Go to page 20 or 22.

5. Treat lawns and ornamentals in and around structures-Lawn and Ornamental (PCO L\&O) or ID Cardholder. Go to page 24 or 30.

6. Applies Fertilizer-Limited Urban Commercial Fertilizer (LUF). Go to page 26.

7. Treat ornamental beds, sidewalks, driveways, NO turf-Limited Commercial Landscape Maintenance (LCLM). Go to page 28. 
Table 3.1. Agriculture or other sites.

1. Do you use a restricted use product (RUP)?
a. Yes-go to Table 3.2.
b. No-see"487 A License Might Not Be Needed" in the key terms on page 1.

Table 3.2. Using restricted use products on agriculture or other sites.

1. Do you apply on property you own or rent, or on property owned or rented by your employer that produces an agricultural commodity?

a. Yes-Private. Go to page 32.

b. No-go to 2.

2. Do you work in agriculture production? (crops, fields, seeds, forests, sod, livestock)

a. Yes-go to Table 3.3.

b. No-go to 3.

3. Do you apply in nonagriculture sites? (natural areas, golf courses, cemeteries, parks, athletic fields, water)

a. Yes-go to Table 3.4.

Table 3.3. Restricted use applicators in agriculture production areas (crops, fields, seeds, livestock).

Do you apply to:

1. Agricultural Row Crop-Production crops (not trees); includes row crops, grains, forage, vegetables, small fruits not produced on trees, pastures; no fumigation. Go to page 34.

2. Agricultural Tree Crop-Applications to production trees; includes citrus, blueberries, pecans, or crop grown on woody shrubs/trees; no fumigation. Go to page 36.

3. Seed Treatment-Seeds; no fumigation. Go to page 38.

4. Soil and Greenhouse Fumigation-Fumigant injections or applications to field soils, containerized plants, potting soil, lawns, turf, and ornamentals not associated with structures; or within enclosed agricultural structures such as greenhouses where agricultural production is in progress. Go to page $\mathbf{4 0 .}$

5. Raw Agricultural Commodity Fumigation-Fumigation to any postharvest raw ag commodity or applied to ag storage facilities. Go to page 42.

6. Aerial-Applications from an aircraft. Go to page 44.

7. Agricultural Animal-Applications to animals, in or on places where such animals are kept or confined (includes swine, cattle, sheep, horses, fish, poultry, bees, and other agricultural livestock). Go to page 46.

8. Forest-Use of pesticides in forests, forest nurseries, or forest seed orchards. Go to page 48.

9. Ornamental and Turf-Production of ornamental trees, shrubs, flowers, or sod. Go to page $\mathbf{5 0 .}$

Table 3.4. Restricted use applicators in nonagriculture areas (natural areas, golf courses, cemeteries, parks, athletic fields, water).

\section{Do you apply to:}

1. Natural Areas-Use herbicides to control vegetation to protect natural communities and ecosystems in natural areas. Go to page 52.

2. Aquatics-Applications to water, standing or running water, banks or shorelines.Excludes chlorine gas and public health activities. Go to page 54.

3. Ornamental and Turf-Maintenance of ornamental plants or sod. Also includes turfgrass growing in or on cemeteries, golf courses, parks, or athletic fields. Does not include lawns around strucutres. Go to page 50. (For lawns around structures, see pages 12 and 24.$)$

4. Right-of-Way-Maintenance of right-of-way areas associated with public roads, electric power lines, pipelines, railroads, and other similar areas. Go to page 56.

5. Other-Wood treatment, antifouling paint, sewer root, chlorine gas infusion, regulatory, demonstration and research. Go to pages 58-70. 


\section{Quick Reference to Pesticide License Page}

\begin{tabular}{|c|c|}
\hline Public Health-6 & Seed Treatment-38 \\
\hline Mosquito Control Director-8 & Soil and Greenhouse Fumigation-40 \\
\hline Limited Structural-10 & Raw Ag Commodity Fumigation-42 \\
\hline Limited Lawn and Ornamental-12 & Aerial-44 \\
\hline Limited Wildlife-14 & Agricultural Animal—46 \\
\hline General Household Pest (PCO GHP)—16 & Forest-48 \\
\hline Wood Destroying Organisms (PCO WDO)_-18 & Ornamental and Turf- 50 \\
\hline Structural Fumigation (PCO FUM) -20 & Natural Areas-52 \\
\hline Special ID Cardholder-22 & Aquatics -54 \\
\hline Lawn and Ornamental (PCO L\&O)-24 & Right-of-way-56 \\
\hline Limited Urban Commercial Fertilizer-26 & Wood Treatment-58 \\
\hline Limited Commercial Landscape Maint._-28 & Organotin Antifouling Paint-60 \\
\hline ID Cardholder-30 & Sewer Root-62 \\
\hline Private-32 & Chlorine Gas-64 \\
\hline Agricultural Row Crop-34 & Regulatory Pest Control-66 \\
\hline \multirow[t]{2}{*}{ Agricultural Tree Crop-36 } & Regulatory Inspection and Sampling -68 \\
\hline & Demonstration and Research-70 \\
\hline
\end{tabular}




\section{Public Health}

- Treatment of mosquitos and other public health pests.

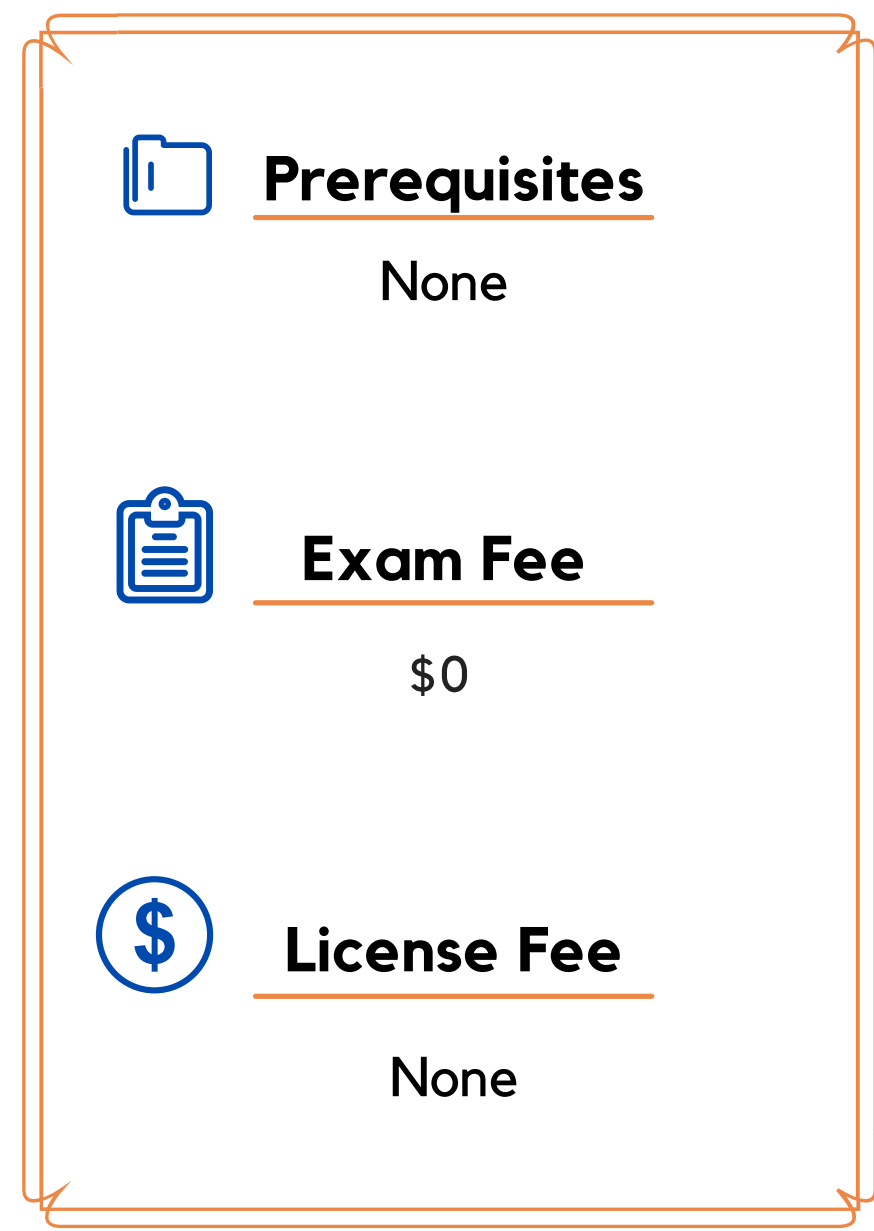

Applying Pesticides
Correctly

WWW.IFASBOOKS.COM
SM 1

\section{Study Material}

Public Health Pest Control

Applicator Training Manual

HTTPS://WWW.FDACS.GOV/EZS3DOWNLOAD/DO WNLOAD/22731/515312/MEDIA/FILES/AGRICULT URAL-ENVIRONMENTAL-SERVICES-

FILES/PUBLIC-HEALTH-MANUAL-2019.PDF

\section{Exam Information}

- Public Health Exam AND General Standards (CORE) Exam

- 50 questions each, multiple-choice and true-false

- 2 hours per exam

- Must pass with $70 \%$

- If performing applications by aircraft, you must pass the aerial exam, page 44.

Schedule your exam at https://pesticideexam.ifas.ufl.edu 


\section{Public Health}

\section{RENEWAL INFORMATION}
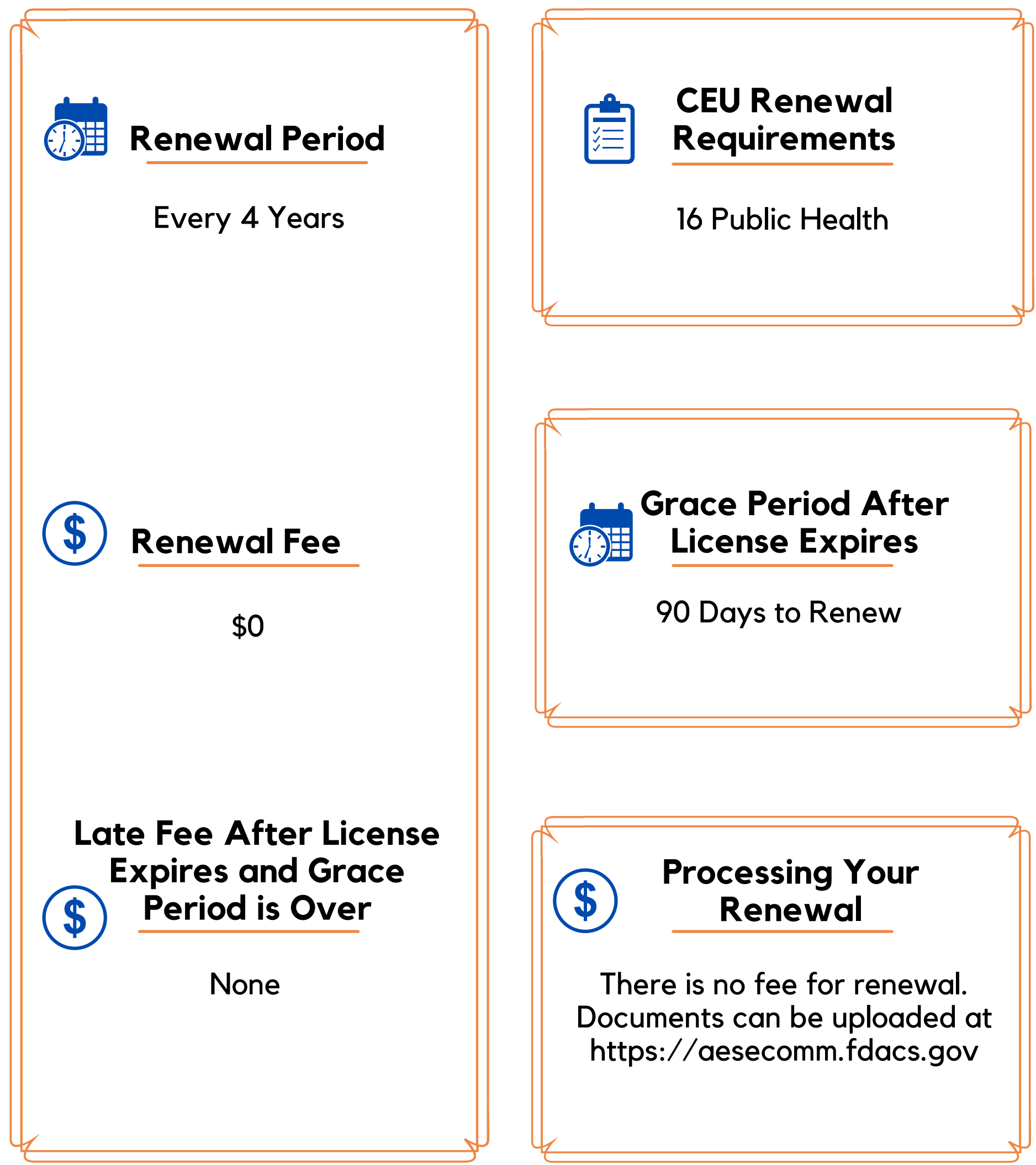

\section{Grace Period After \\ (i) License Expires \\ 90 Days to Renew}

\section{\$ Processing Your \\ \$ Renewal}

There is no fee for renewal. Documents can be uploaded at https://aesecomm.fdacs.gov 


\section{Mosquito Control Director}

- For Mosquito Control Directors. A requirement for ALL Directors of Public Mosquito Programs. Must also have a license in Public Health.

\section{$11]$ Prerequisites}

Must hold a valid Public Health Pest Control License and obtain approval from FDACS to take the exam

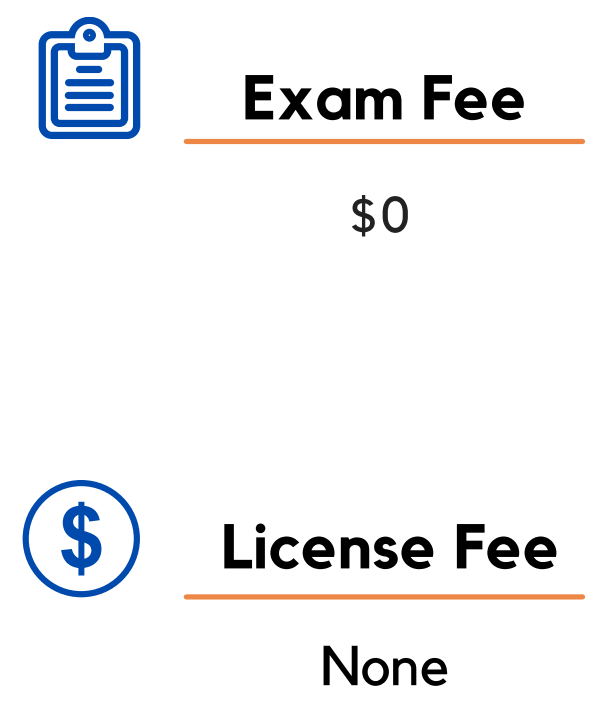

\section{Study Material}

Applying Pesticides Correctly

WWW.IFASBOOKS.COM

Public Health Pest Control Applicator Training Manual

HTTPS://WWW.FDACS.GOV/EZS3DOWNLOAD/DOWNLOAD/2 2731/515312/MEDIA/FILES/AGRICULTURALENVIRONMENTAL-SERVICES-FILES/PUBLIC-HEALTHMANUAL-2019.PDF

Chapter 388 FL Statute

Rule 5E-13

Florida Mosquito Control Handbook

HTTPS://FMEL.IFAS.UFL.EDU/MEDIA/FMELIFASUFLED U/7-15-2018-WHITE-PAPER.PDF

\section{弱 Exam Information}

- Mosquito Control Directors exam

- Primarily essay exam, must pass with $70 \%$

- 4 hours per exam

- Extension offices should contact FDACS for exam several weeks prior to the test date

Schedule your exam by contacting your local Extension Office at https://pesticideexam.ifas.ufl.edu 


\section{Mosquito Control Director}

\section{RENEWAL INFORMATION}

\section{(1) Renewal Period}

Remains valid so long as Public Health Control License is valid

(\$) Renewal Fee $\$ 0$

Late Fee After License $\$$ Expires and Grace Period is Over

None
送 $\begin{aligned} & \text { CEU Renewal } \\ & \text { Requirements }\end{aligned}$

Maintain Public Health Control License

\section{Grace Period After} License Expires

None

\section{(\$) Processing Your}

There is no fee for renewal.

Documents can be uploaded at https://aesecomm.fdacs.gov 


\section{Limited Structural}

- Government employees and private property doing pest control on structures. Cannot work "for hire."

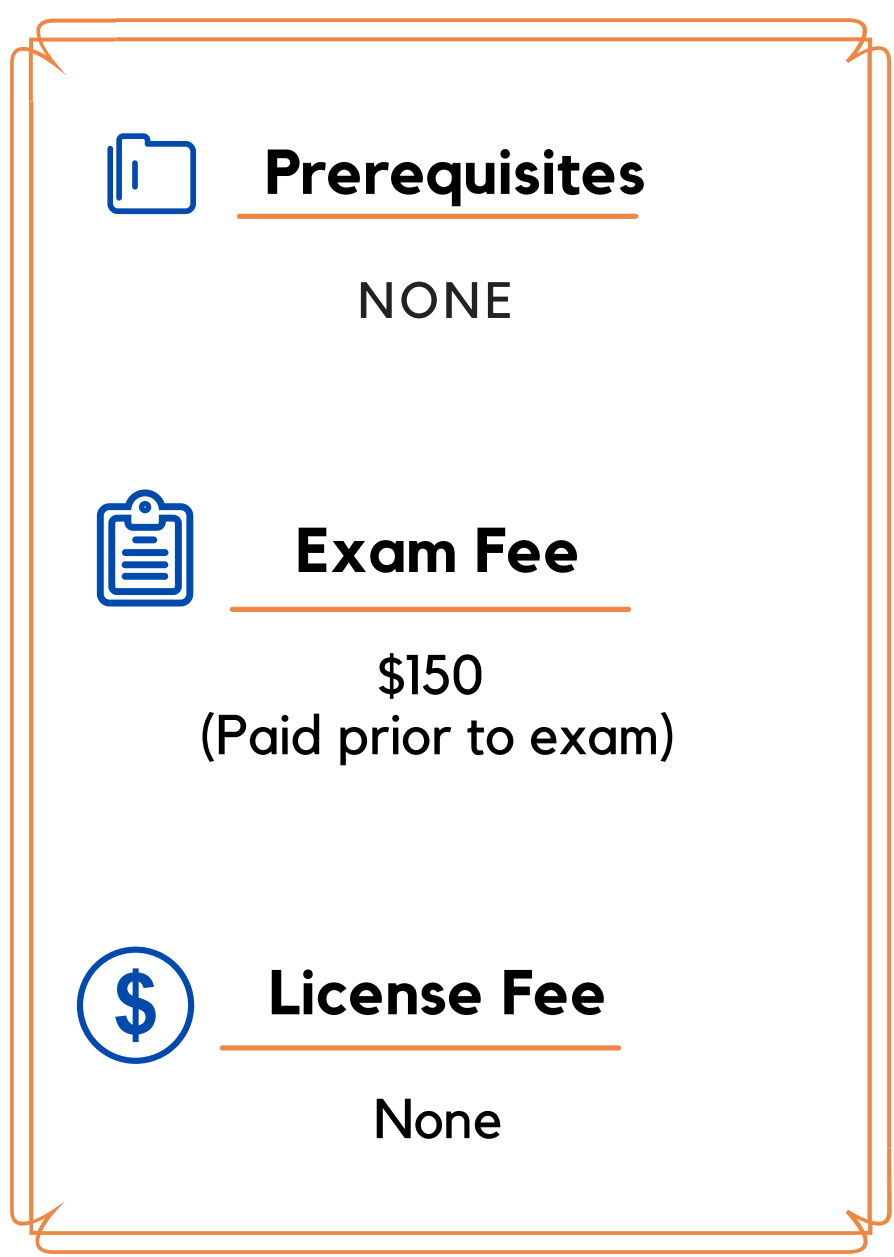

\section{渴 Exam Information}

- Limited Structural Exam

- 80 questions, multiplechoice

- 2 hours per exam

- Must pass with 75\%

Schedule your exam at https://pesticideexam.ifas.ufl.edu

\section{Study Material}

Applying Pesticides

SM 1

Correctly

WWW.IFASBOOKS.COM

General Household

SM 47

Pest Control Applicator

Training Manual

WWW.IFASBOOKS.COM

The Structural Pest Control Act, Chapter 482, Florida Statutes (1)

Rules of the Department of Agriculture and Consumer Services, Chapter 5E-14, Florida Administrative Code (1) 


\section{Limited Structural}

\section{RENEWAL INFORMATION}
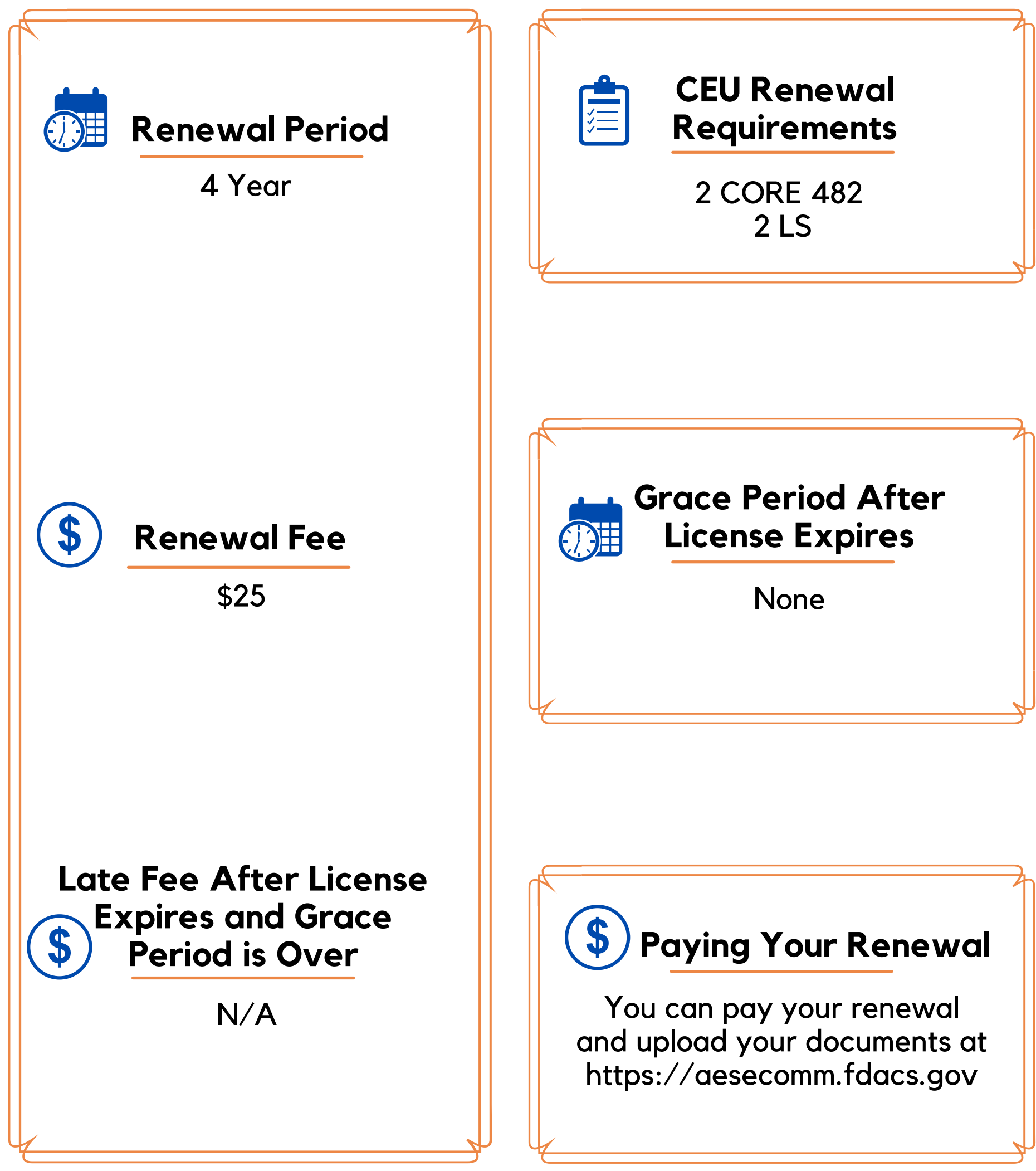

\section{Grace Period After} License Expires

None

\$) Paying Your Renewal

You can pay your renewal and upload your documents at https://aesecomm.fdacs.gov 


\section{涪 0 Limited Lawn and Ornamental (LLO)}

- Government employees and private property doing working in lawns/turf and ornamentals around structures.

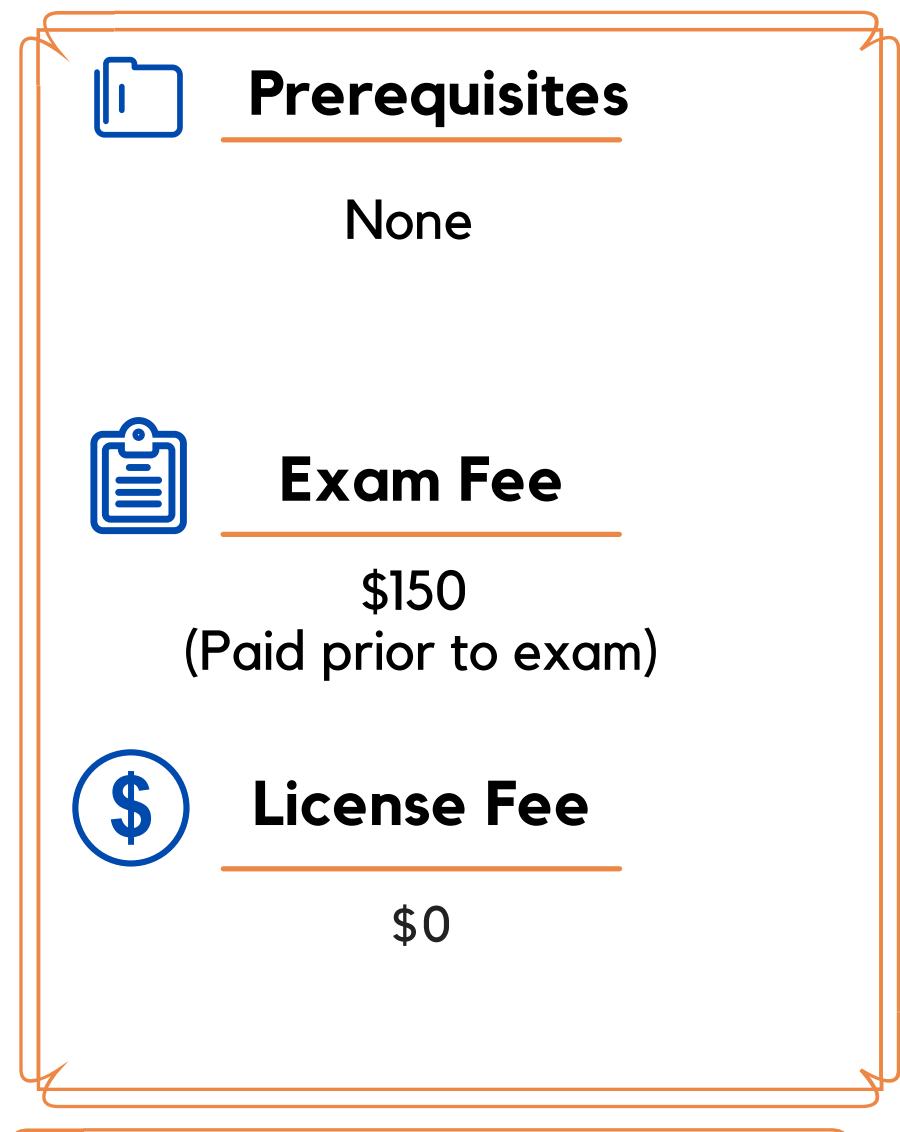

\section{Exam Information}

- Limited Lawn and Ornamental Exam

- 80 questions, multiplechoice

- 2 hours per exam

- Must pass with $75 \%$

Schedule your exam at https://pesticideexam.ifas.ufl.edu

\section{Study Material}

Applying Pesticides

SM 1

Correctly

WWW.IFASBOOKS.COM

Lawn and Ornamental SM 81 Pest Management

\section{WWW.IFASBOOKS.COM}

Identification Guide to SP 499

Common Florida Lawn

and Ornamental Weeds

WWW.IFASBOOKS.COM

The Structural Pest Control Act, Chapter 482, Florida Statutes (1)

Rules of the Department of Agriculture and Consumer Services, Chapter 5E-14, Florida Administrative Code (1) 


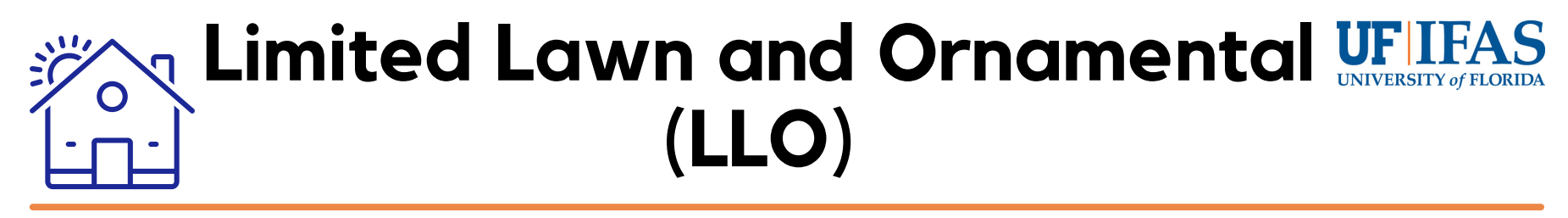

\section{RENEWAL INFORMATION}
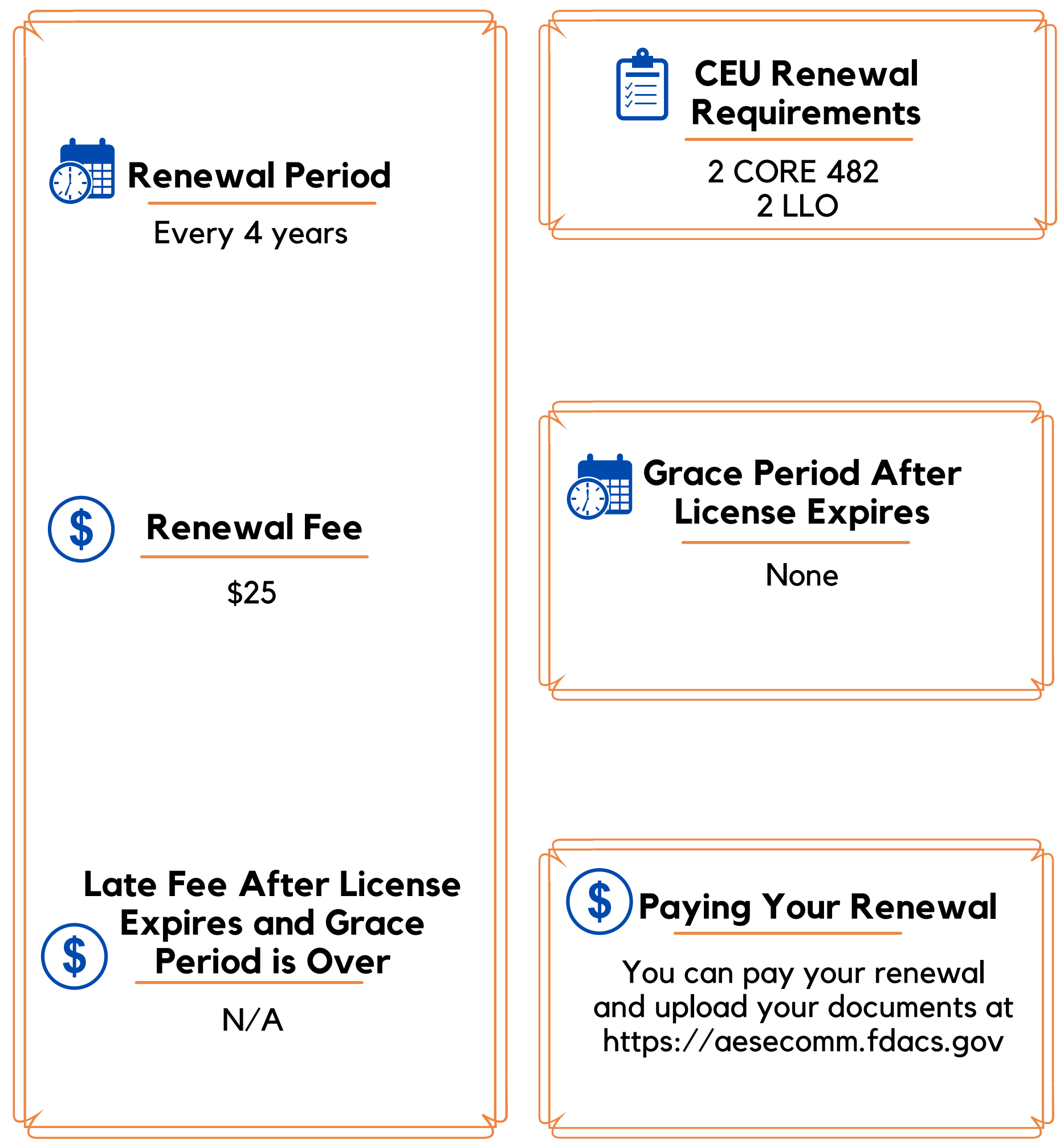

(\$) Paying Your Renewal

You can pay your renewal and upload your documents at https://aesecomm.fdacs.gov 


\section{Limited Wildlife}

- Allows for the trapping and exclusion of rodents from a structure. No baits or pesticides allowed.

- Strictly for exclusion and trapping for rodents on or under structures.

- Does not allow any kind of pesticide applications.

11 Prerequisites

None

Exam Fee

$\$ 150$

(Paid prior to exam)

\$) License Fee

$\$ 0$

\section{Study Material}

Applying Pesticides

Correctly

WWW.IFASBOOKS.COM

Dealing with Unwanted \#WEC20 Wildlife in an Urban

Environment

HTTP://EDIS.IFAS.UFL.EDU/UW070

Non-Chemical

Rodent Control

\#ENY-243

HTTPS://UFDC.UFL.EDU/IR00004258/00001

The Structural Pest Control

Act, Chapter 482, Florida

Statutes (1)

Rat and Mouse

\#ENY-244

Control

HTTP://EDIS.IFAS.UFL.EDU/DHO44

The Florida Mouse

\#WEC362

HTTP://EDIS.IFAS.UFL.EDU/UW307

- 30 questions, multiplechoice

- 2 hours per exam

- Must pass with 75\%

Schedule your exam at https://pesticideexam.ifas.ufl.edu
Rules of the Department of Agriculture and Consumer Services, Chapter 5E-14, Florida Administrative Code (1) 


\section{Limited Wildlife}

\section{RENEWAL INFORMATION}

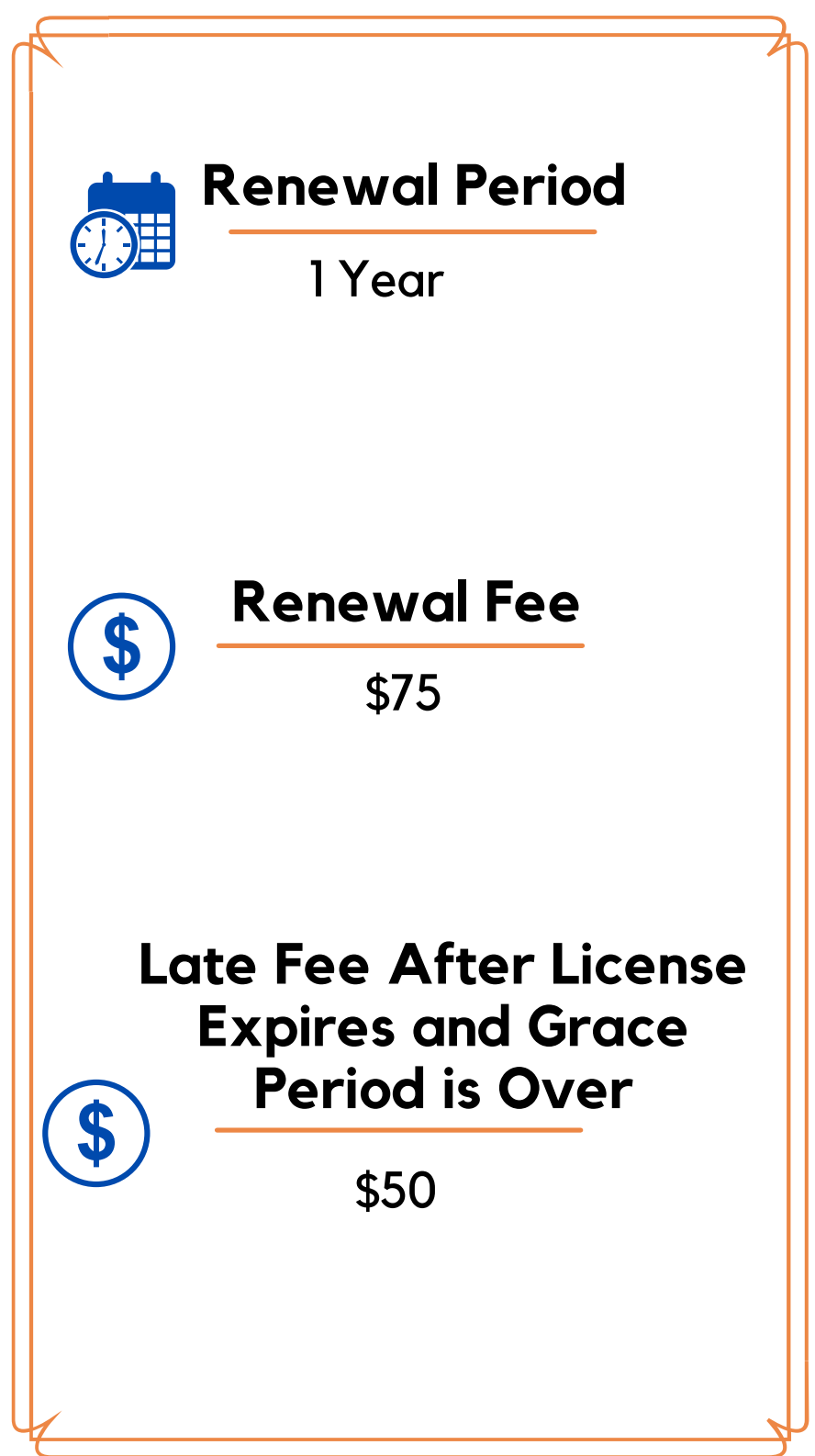

C르 Renewal Requirements

2 CORE 482 2 LW

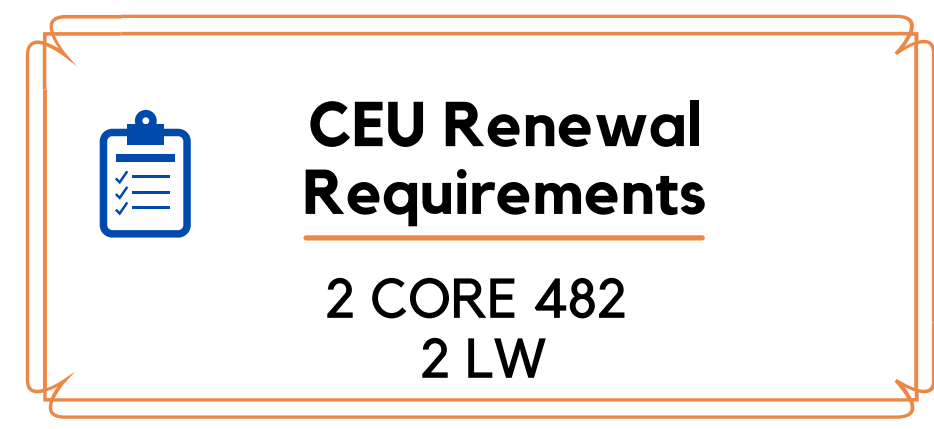

\section{(1) Grace Period After License Expires}

- 180 days to renew

- Late fee charged 30 days after license expiration

\section{\$) Paying Your Renewal}

You can pay your renewal and upload your documents at https://aesecomm.fdacs.gov

\section{Important Info \\ LICENSE REQUIRES PROOF OF MINIMUM INSURANCE}

Bodily injury: $\$ 250,000$ each person and $\$ 500,000$ each occurrence; and property damage $\$ 250,000$ each occurrence and $\$ 500,000$ in the aggregate; or combined single limit coverage of $\$ 500,000$ in the aggregate 


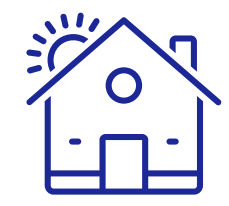

\section{General Household Pest (PCO GHP)}

- Trap or treat household pests and rodents in and around buildings.

\section{Prerequisites}

Must qualify through experience and/or education.

To qualify by experience, you must be able to document:

- A high school education or equivalency and

- Three years experience as an ID cardholder under a licensee in the categories you are seeking certification. At least one of these years must be in Florida and immediately precede your application for examination.

To qualify through education and experience, visit Florida statutes Ch $\mathbf{4 8 2 . 1 3 2}$ for specific requirements. Have 45 documented jobs as an ID cardholder.

\section{Study Material}

Applying Pesticides

SM 1

Correctly

WWW.IFASBOOKS.COM

General Household

SM 47

Pest Control Applicator

Training Manual

WWW.IFASBOOKS.COM

The Structural Pest Control Act, Chapter 482, Florida Statutes (1)

Rules of the Department of Agriculture and Consumer Services, Chapter 5E-14, Florida Administrative Code (1) $\$ 0$

\section{Exam Information}

- General Household Pest exam

- 200 questions, multiple-choice

- 4 hours per exam

- Must pass with $75 \%$

Schedule your exam at https://pesticideexam.ifas.ufl.edu 


\section{General Household Pest (PCO GHP)}

\section{RENEWAL INFORMATION}

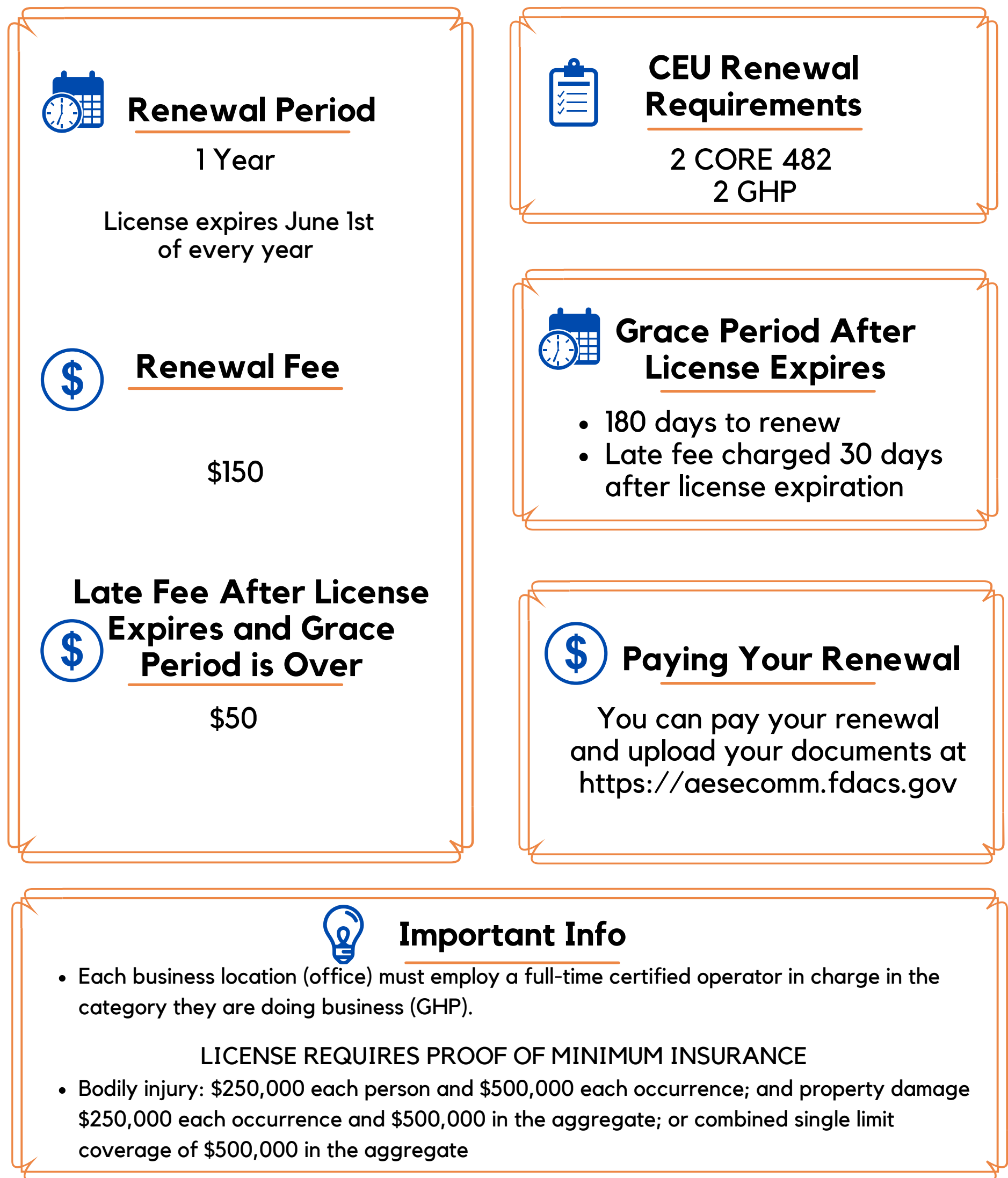




\section{㴆 Wood-Destroying Organisms (PCO WDO)}

- Treat or inspect for termites and other wood-destroying organisms in and around structures, including landscapes.

\section{Prerequisites}

Must qualify through experience and/or education.

To qualify by experience, you must be able to document:

- A high school education or equivalency and

- Three years of experience as an ID cardholder under a licensee in the categories you are seeking certification. At least one of these years must be in Florida and immediately precede your application for examination.

To qualify through education and experience, visit Florida statutes $\mathrm{Ch} \mathbf{4 8 2 . 1 3 2}$ for specific requirements. Have 45 documented jobs as an ID cardholder. No more than 15 of those jobs can be WDO inspections.

\section{[ Exam Fee}

$\$ 300$

(Nonrefundable)

\$) License Fee

$\$ 0$

\section{Exam Information}

- Wood-Destroying Organisms exam

- 200 questions, multiple-choice

- 4 hours per exam

- Must pass with $75 \%$

Schedule your exam at https://pesticideexam.ifas.ufl.edu

\section{Study Material}

Applying Pesticides

SM 1

Correctly

WWW.IFASBOOKS.COM

Construction and

Building Terms Relevant

to a Pest Inspection to a

Pest Inspection and

Wood-Destroying

Organisms Applicator

Training Manual

WWW.IFASBOOKS.COM

The Structural Pest Control Act, Chapter 482, Florida Statutes (1)

Rules of the Department of Agriculture and Consumer Services, Chapter 5E-14, Florida Administrative Code (1) 


\section{沙合 \\ Wood-Destroying Organisms (PCO WDO)}

\section{RENEWAL INFORMATION}
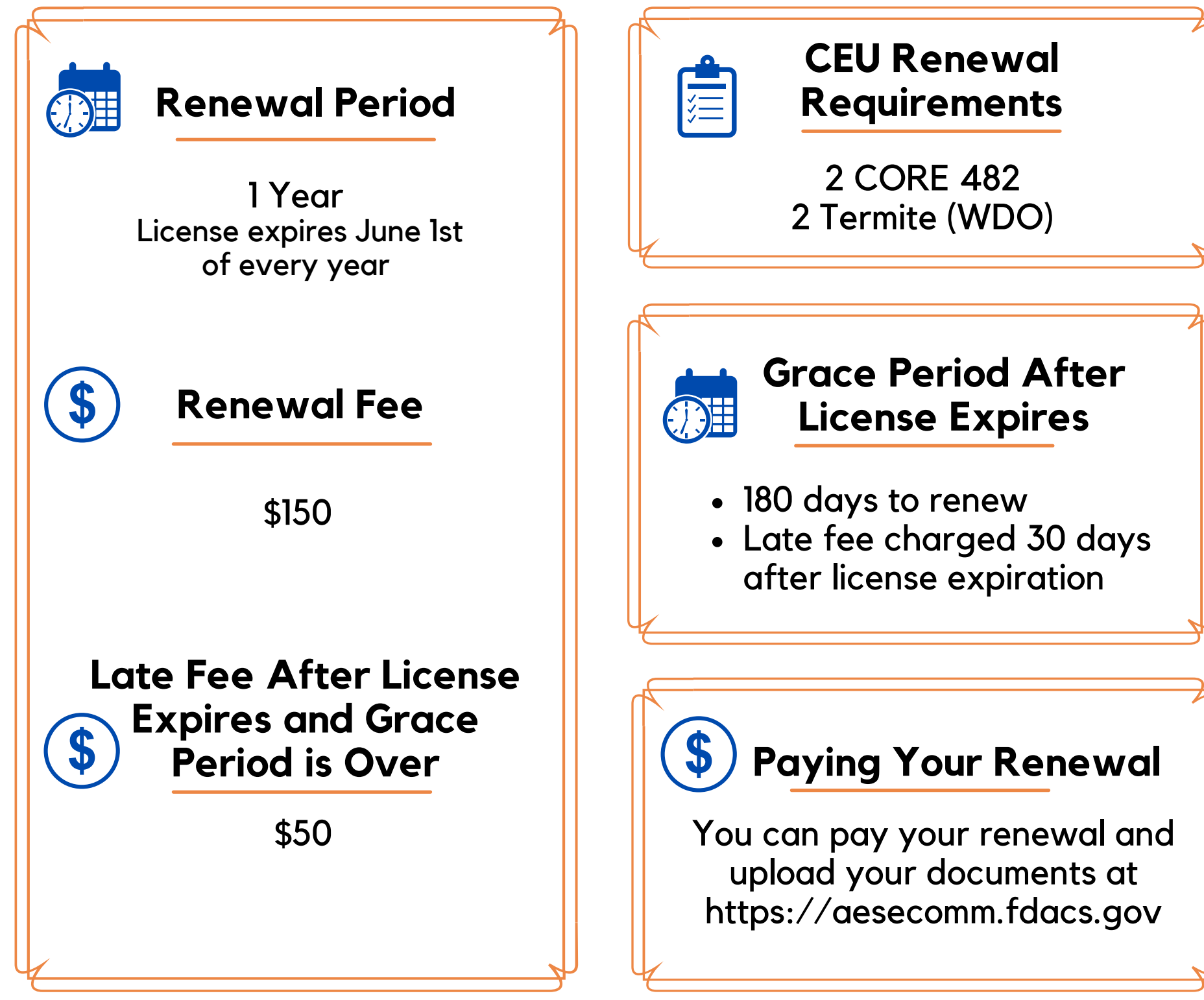

Grace Period After License Expires

- 180 days to renew

- Late fee charged 30 days after license expiration

\section{(\$) Paying Your Renewal}

You can pay your renewal and upload your documents at https://aesecomm.fdacs.gov

\section{2) Important Info}

- Each business location (office) must employ a full-time certified operator in charge in the category they are doing business (WDO).

LICENSE REQUIRES PROOF OF MINIMUM INSURANCE

- Bodily injury: $\$ 250,000$ each person and $\$ 500,000$ each occurrence; and property damage $\$ 250,000$ each occurrence and $\$ 500,000$ in the aggregate; or combined single limit coverage of $\$ 500,000$ in the aggregate 


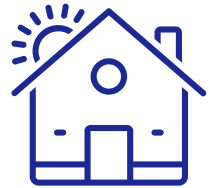 \\ Structural Fumigation (PCO FUM)}

- Fumigate structures for wood-destroying organisms.

\section{Prerequisites}

Must qualify through experience and/or education.

To qualify by experience, you must be able to document:

- A high school education or equivalency and

- Three years of experience as an ID cardholder under a licensee in the categories you are seeking certification. At least one of these years must be in Florida and immediately precede your application for examination.

To qualify through education and experience, visit Florida statutes Ch $\mathbf{4 8 2 . 1 3 2}$ for specific requirements. Have 15 documents of fumigation jobs as an ID cardholder.

Exam Fee

$\$ 300$

(Nonrefundable)

(\$) License Fee

$\$ 0$

\section{Study Material}

Applying Pesticides

SM 1

Correctly

WWW.IFASBOOKS.COM

2021 Florida Fumigation SP340

Manual

HTTPS://FLREC.IFAS.UFL.EDU/FLORIDA-FUMIGATION-MANUAL/

The Structural Pest Control Act, Chapter 482, Florida Statutes (1)

Rules of the Department of Agriculture and Consumer Services, Chapter 5E-14, Florida Administrative Code (1)

\section{Exam Information}

- Fumigation Exam

- 200 questions, multiple-choice

- 4 hours per exam

- Must pass with $75 \%$

Schedule your exam at https://pesticideexam.ifas.ufl.edu 


\section{Structural Fumigation (PCO FUM)}

\section{RENEWAL INFORMATION}

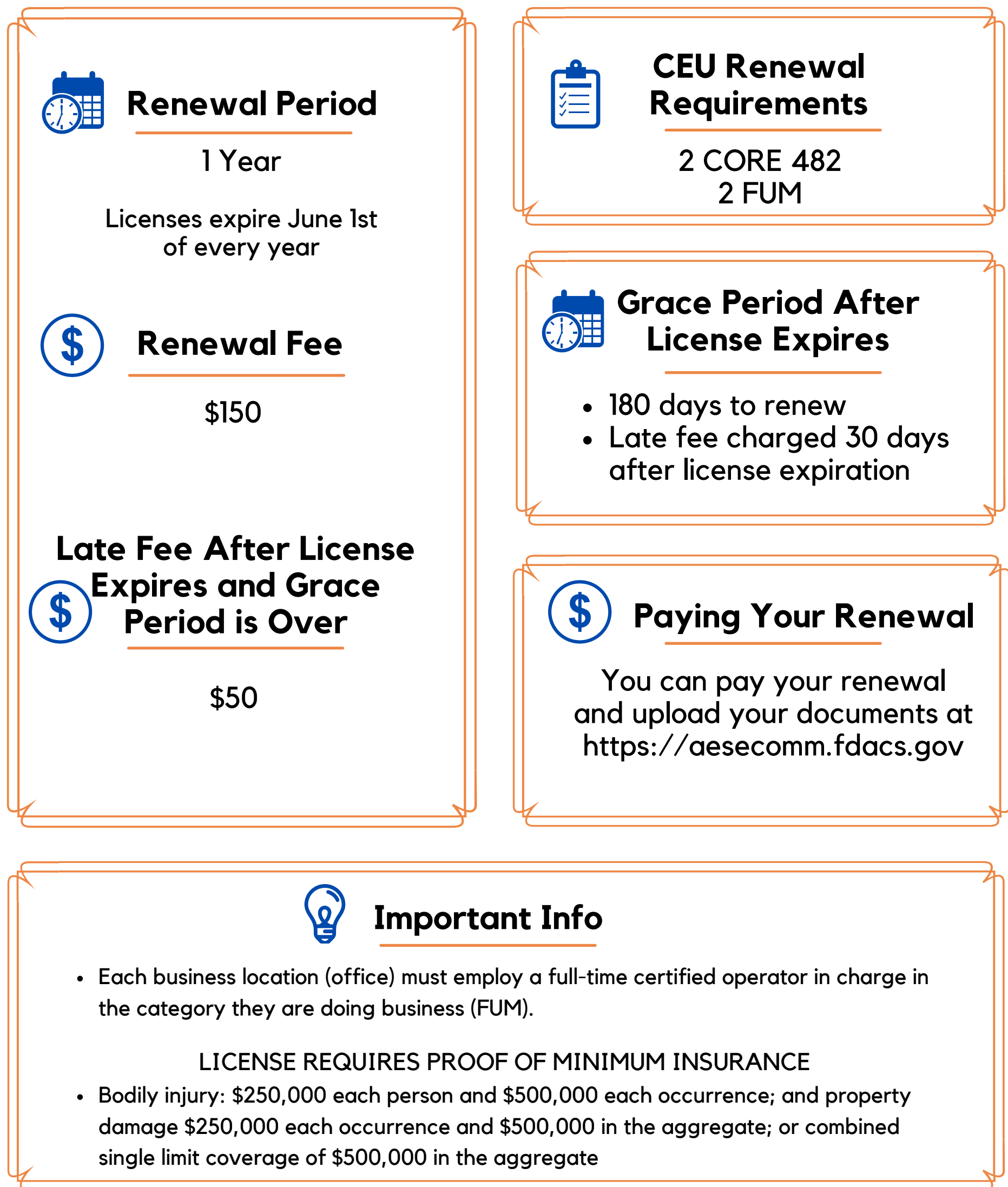




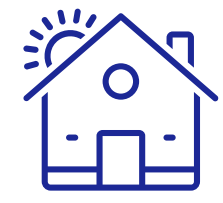

\section{Special ID Cardholder in Fumigation}

- Allowed to serve as a primary or secondary person during a fumigation. Cannot serve as CPO in charge.

(1) Prerequisites

Must be ID Cardholder

15 documented fumigation jobs

Exam Fee $\$ 200$

(\$) License Fee $\$ 0$

\section{Study Material}

Applying Pesticides

SM 1

Correctly

WWW.IFASBOOKS.COM

2005 Florida

SP340

Fumigation Manual

HTTPS://WWW.FDACS.GOV/EZS3DOWNLOAD/DOWNLOAD/427 27/989146/MEDIA/FILES/AGRICULTURAL-ENVIRONMENTALSERVICES-FILES/SP340\%20130CT04.PDF

The Structural Pest Control Act, Chapter 482, Florida Statutes (1)

Rules of the Department of Agriculture and Consumer Services, Chapter 5E-14, Florida Administrative Code (1)

\section{涅 1 Exam Information}

- Special ID Card Exam

- 100 questions, multiple-choice

- 3 hours per exam

- Must pass with $75 \%$

Schedule your exam at https://pesticideexam.ifas.ufl.edu 


\section{Special ID Cardholder in Fumigation

\section{RENEWAL INFORMATION}

\section{(i) Renewal Period}

1 Year

Licenses expire June lst of every year

(\$) Renewal Fee $\$ 100$

Late Fee After License Expires and Grace \$) Period is Over $\$ 25$

\section{CEU Renewal \\ Requirements}

2 CORE 482 and 2 FUM

\section{Grace Period After}

(1) License Expires

- 180 days to renew

- Late fee charged 30 days after license expiration
(\$) Paying Your Renewal

You can pay your renewal and upload your documents at

https://aesecomm.fdacs.gov

\section{Important Info \\ LICENSE REQUIRES PROOF OF MINIMUM INSURANCE}

Bodily injury: $\$ 250,000$ each person and $\$ 500,000$ each occurrence; and property damage $\$ 250,000$ each occurrence and $\$ 500,000$ in the aggregate; or combined single limit coverage of $\$ 500,000$ in the aggregate 


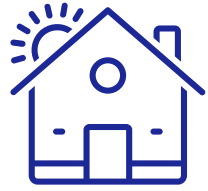 \\ Lawn and Ornamental (PCO L\&O)}

- Treat lawns and ornamentals in and around structures.

\section{Prerequisites}

Must qualify through experience and/or education.

To qualify by experience, you must be able to document:

- A high school education or equivalency and

- Three years of experience as an ID cardholder under a licensee in the categories you are seeking certification. At least one of these years must be in

Florida and immediately precede your application for examination.

To qualify through education and experience, visit

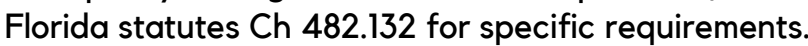
Have 45 documented jobs as an ID cardholder.

\section{Exam Fee}

$\$ 300$

(Nonrefundable)

(\$) License Fee

$\$ 0$

\section{Study Material}

Applying Pesticides

Correctly

WWW.IFASBOOKS.COM

Identification

SP 499

Guide to Common Florida Lawn and Ornamental Weeds

WWW.IFASBOOKS.COM

Lawn and Ornamental

Pest Management

WWW.IFASBOOKS.COM

The Structural Pest Control Act, Chapter 482, Florida Statutes (1)

Rules of the Department of Agriculture and Consumer Services, Chapter 5E-14, Florida Administrative Code (1)

Management Practices for Protection of Water Resources in Florida

HTTP://FFL.IFAS.UFL.EDU/PROFESSIONALS/BMP_MANUAL.HTM 


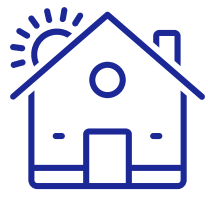

\section{RENEWAL INFORMATION}
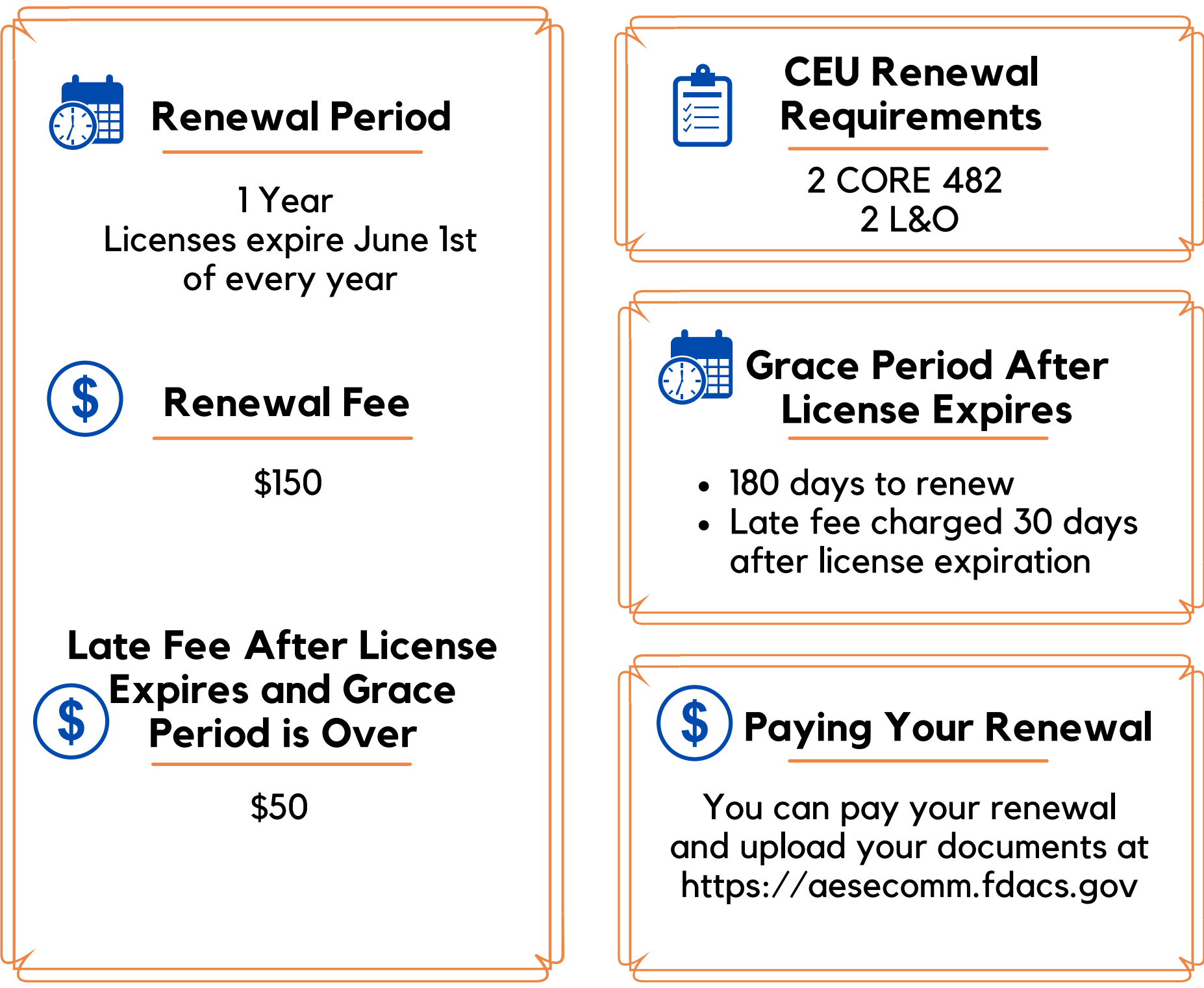

Grace Period After
License Expires

- 180 days to renew

- Late fee charged 30 days after license expiration

\section{\$) Paying Your Renewal}

You can pay your renewal and upload your documents at https://aesecomm.fdacs.gov

\section{Important Info}

- Each business location (office) must employ a full-time certified operator in charge in the category they are doing business (L\&O).

\section{LICENSE REQUIRES PROOF OF MINIMUM INSURANCE}

- Bodily injury: $\$ 250,000$ each person and $\$ 500,000$ each occurrence; and property damage $\$ 250,000$ each occurrence and $\$ 500,000$ in the aggregate; or combined single limit coverage of $\$ 500,000$ in the aggregate 


\section{Limited Urban Commercial Fertilizer (LUF)}

- For those using fertilizers in lawns/turf around structures. No pesticides are allowed with this license (no weed and feed).

\section{Prerequisites}

Attend and successfully earn the Green Industries Best Management Practices for the Protection of Water Resources certification (GIBMP)

HTTPS://GIBMP.IFAS.UFL.EDU

Exam Fee

None

EXAM IS COMPLETED DURING THE GIBMP WORKSHOP

\section{(\$) License Fee} $\$ 25$

\section{Study Material}

Green Industries Best

Management Practices for the

Protection of Water Resources

(GIBMP) Manual

HTTPS://FFL.IFAS.UFL.EDU/FFL-AND-YOU/GI-

BMP-PROGRAM/GI-BMP-MANUAL/

The Structural Pest Control Act, Chapter 482, Florida Statutes (1)

Rules of the Department of Agriculture and Consumer Services, Chapter 5E-14, Florida Administrative Code (1)

\section{淐 Exam Information}

- There is no state exam for this license.

- There is an exam that is given during the GIBMP workshop that must be passed with $75 \%$ to receive certificate. 


\section{Limited Urban Commercial Fertilizer (LUF)}

\section{RENEWAL INFORMATION}
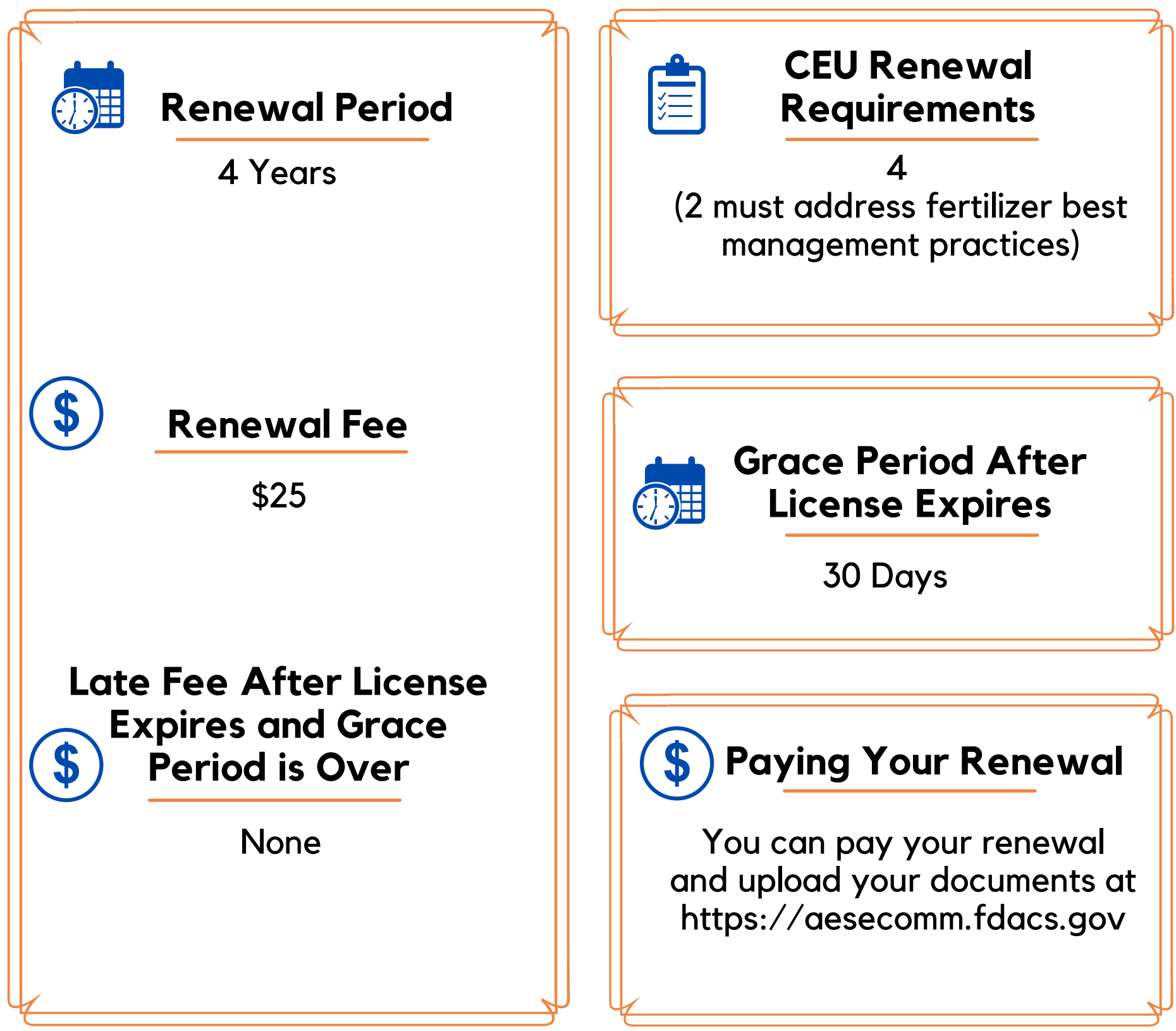

\section{(\$) Paying Your Renewal}

You can pay your renewal and upload your documents at https://aesecomm.fdacs.gov

\section{2) Important Info}

- Does not allow supervision of noncertified fertilizer applicators.

- No applications using pesticides, including pesticide/fertilizer mixes, are allowed.

- Yard workers who apply fertilizer only to individual residential properties using fertilizer and equipment provided by the residential property owner or resident are exempt from the requirements of this section. 


\section{Limited Commercial Landscape Maintenance (LCLM)}

- For professionals who treat ornamental plants and beds around buildings.

- No turf applications allowed.

- Restricted to 3-gallon pressurized and no power equipment.

- No more than a 5-gallon backpack.

- "Caution" labelled products only.

- Proof of insurance is required upon passing the exam.

\section{Prerequisites}

COMPLETE 6 HOURS OF TRAINING

ANY COMBINATION OF LCLM,

CORE 482, LLO, L\&O

를

Exam Fee

$\$ 150$

Paid prior to exam

\$) License Fee

None

\section{Study Material}

Applying Pesticides

SM 1

Correctly

WWW.IFASBOOKS.COM

Limited Commercial

SM 82

Landscape Maintenance

WWW.IFASBOOKS.COM

Identification Guide to SP 499 Common Florida Lawn and Ornamental Weeds

WWW.IFASBOOKS.COM

The Structural Pest Control Act, Chapter 482, Florida Statutes (1)

- Limited Commercial Landscape Maintenance Exam

- 80 questions, multiple-choice

- 2 hours per exam

- Must pass with $75 \%$

Schedule your exam at https://pesticideexam.ifas.ufl.edu

Rules of the Department of Agriculture and Consumer Services, Chapter 5E-14, Florida Administrative Code (1) 


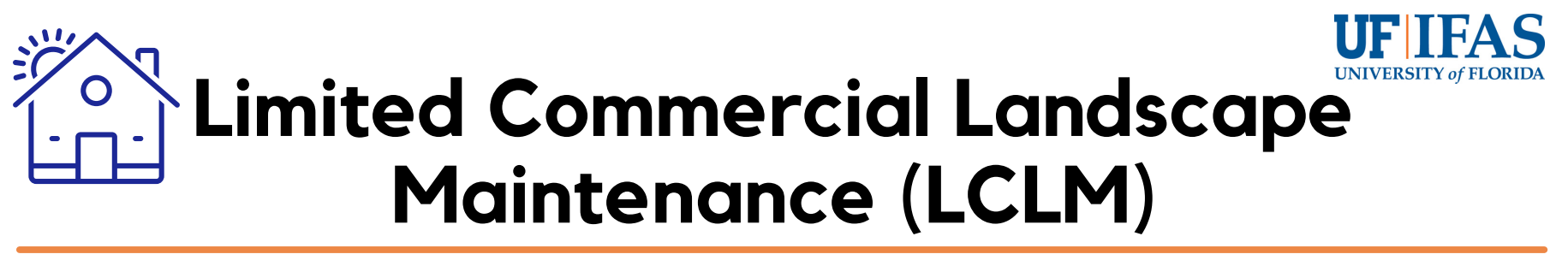

RENEWAL INFORMATION

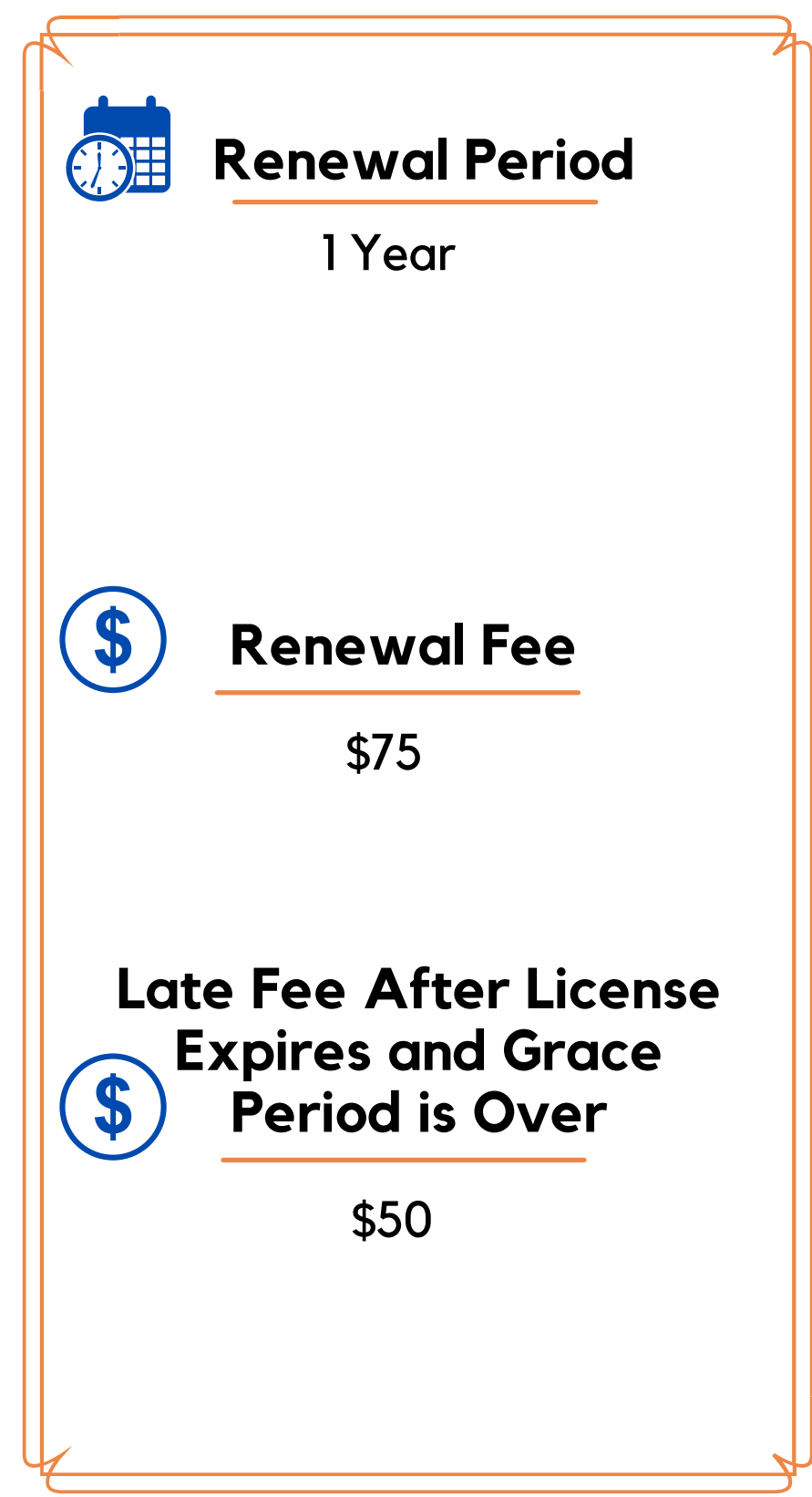

送 CEU Renewal

4

(related to plant bed and ornamental education)

\section{Grace Period After if License Expires \\ - 180 days to renew \\ - Late fee charged 30 days after license expiration}

\section{(\$) Paying Your Renewal}

You can pay your renewal and upload your documents at https://aesecomm.fdacs.gov

\section{Q) Important Info}

\section{LICENSE REQUIRES PROOF OF MINIMUM INSURANCE}

Bodily injury: $\$ 250,000$ each person and $\$ 500,000$ each occurrence; and property damage $\$ 250,000$ each occurrence and $\$ 500,000$ in the aggregate; or combined single limit coverage of $\$ 500,000$ in the aggregate 


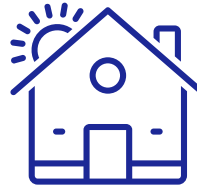

\section{Identification Cardholder}

- ID Card is for individuals who work under a Certified Pest Control Operator in one or more of the categories of Lawn and Ornamental, General Household Pests, Wood-Destroying Organisms, or Fumigation.

- For fumigation and wood-destroying organism ID Cardholders, refer to the additional boxes for more information.

\section{Prerequisites}

Must work for a Certified Pest Control Operator in the category of the ID Card.

Initial Training Requirement-An employee may not perform, solicit, inspect, or apply pest control without first having been provided at least 5 days ( 40 hours) of field training in the appropriate category of pest control under the direct supervision, direction, and control of a certified operator. Use form:

http://forms. freshfromflorida.com/13665.pdf (Chapter 482.091, F.S. and 5E-14.1421 F.A.C.)

\section{Termites and Wood-} Destroying Organisms

ID Cardholders who perform inspections and annual renewals for wood-destroying organisms must have training and apply for a WDO inspection endorsement. Special training is required and should be documented.

(CH 482.226, F.S.)

\section{Study Material}

None

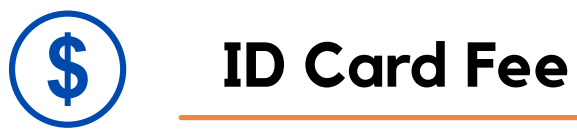

There is a $\$ 10$ application fee for card (not a license).

\section{Fumigations}

There are three levels of ID cardholders for the fumigation category. Levels are based on training and testing. Please refer to rules and statues for specifics.

- ID Cardholders under a Certified Pest Operator in fumigation. These individuals receive initial 40 hours training (CH 482.091(3) F.S.); qualifies them to assist at fumigation site such as, but not limited to tarping.

- Fumigation Identification Card Endorsement (FID)-qualifies individual as the second trained fumigation person; annual fumigation training requirements beyond regular ID Cardholder (5E-14.108 F.A.C. and 5E-14.1421(5), F.A.C.).

- Special Identification Cardholder in Fumigation (SPID)-allows cardholder to serve as first person for fumigation; exam and training required; refer to SPID information sheet for exam specifics (5E-14.108 F.A.C.). 


\section{Identification Cardholder}

\section{RENEWAL INFORMATION}

\section{(1) Renewal Period}

Every year on the licensee's (business) anniversary date set by FDACS for each licensed business location.

\section{\$) Renewal Fee} $\$ 10$

Late Fee After License

Expires and Grace Period is Over

None

\section{을 CEU Renewal Requirements}

4 hours during the first 6 months of employment in pesticide safety, integrated pest management, and applicable federal and state laws and rules.

2 hours each year following. Technician training hours can be provided by the Certified Pest Control Operator and documented or via an FDACS approved CEU provider in CORE.

\section{Grace Period After} License Expires

None

\$) Paying Your Renewal

You can pay your renewal and upload your documents at https://aesecomm.fdacs.gov 


\section{Private Applicator}

- For production of crops, livestock or other agricultural products that are entirely on property owned by the applicator, or land leased by the applicator.

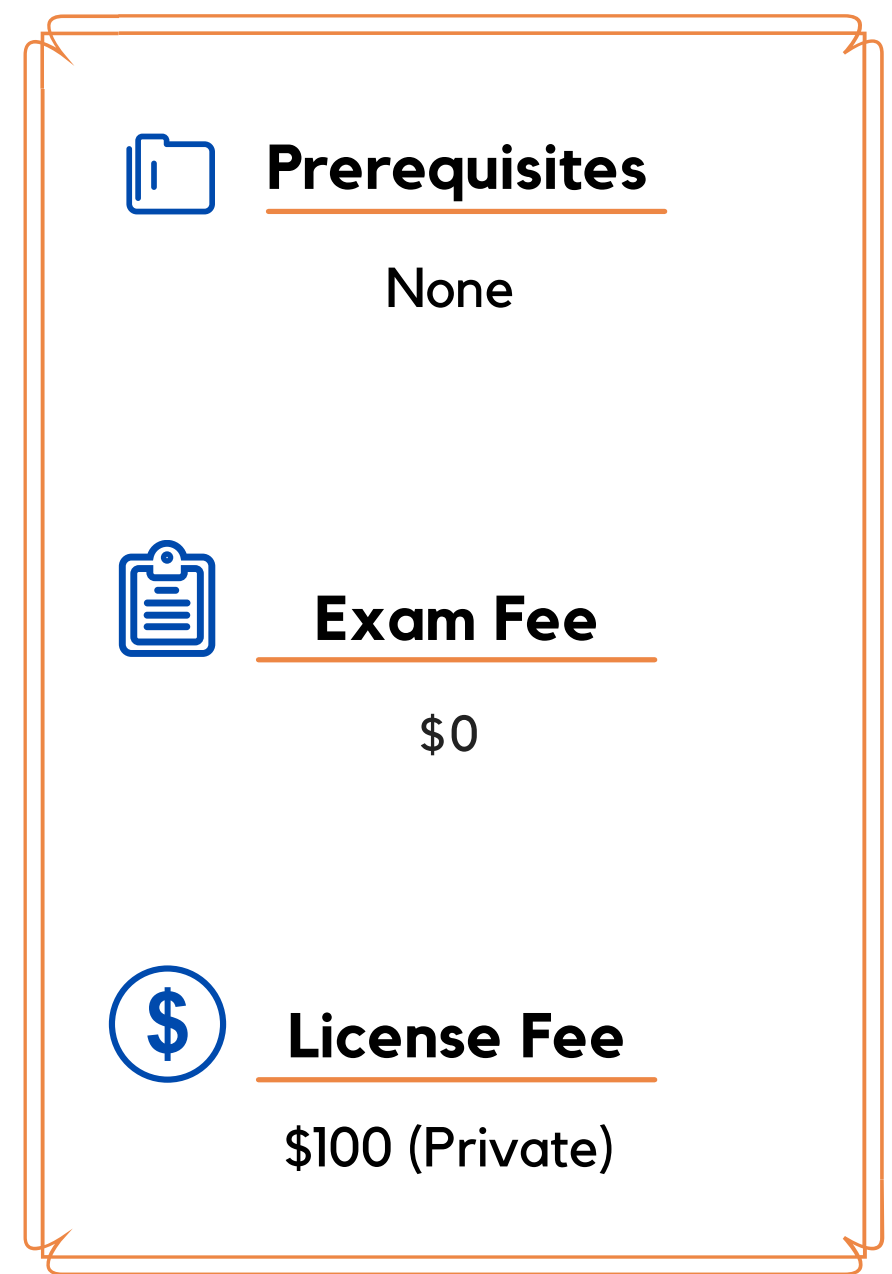

Private Applicator

SM 53

Agricultural Pest Control

Applying Pesticides Correctly

SM 1

Study Material

WWW.IFASBOOKS.COM

WWW.IFASBOOKS.COM

\section{Exam Information}

- Private exam AND General Standards (CORE) Exam

- 50 questions each, multiple-choice

- 2 hours per exam

- Must pass with $70 \%$

Schedule your exam at https://pesticideexam.ifas.ufl.edu 
Dis

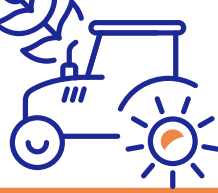

Private Applicator

RENEWAL INFORMATION

\section{(1) Renewal Period}

4 years

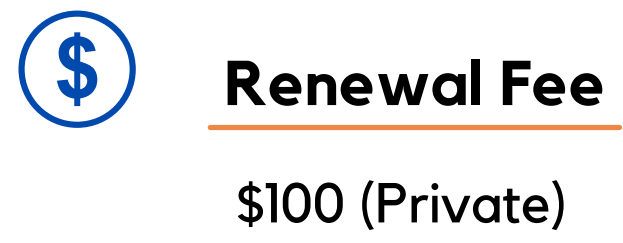

Late Fee After License

(\$) Expires and Grace Period is Over

$\$ 50$
量 CEU Renewal

Requirements

4 CORE

4 Private Applicator

\section{Grace Period After}

(1) License Expires

- 365 days to renew

- Late fee charged 60 days after license expiration
\$) Paying Your Renewal

You can pay your renewal and upload your documents at https://aesecomm.fdacs.gov 


\section{Agricultural Row Crop}

- Production crops (not trees); includes row crops, grains, forage, vegetables, small fruits not produced on trees, pastures (not for sod production) and other fallow agricultural land. Use of RUP fumigants requires "Soil and Greenhouse Fumigation" license.

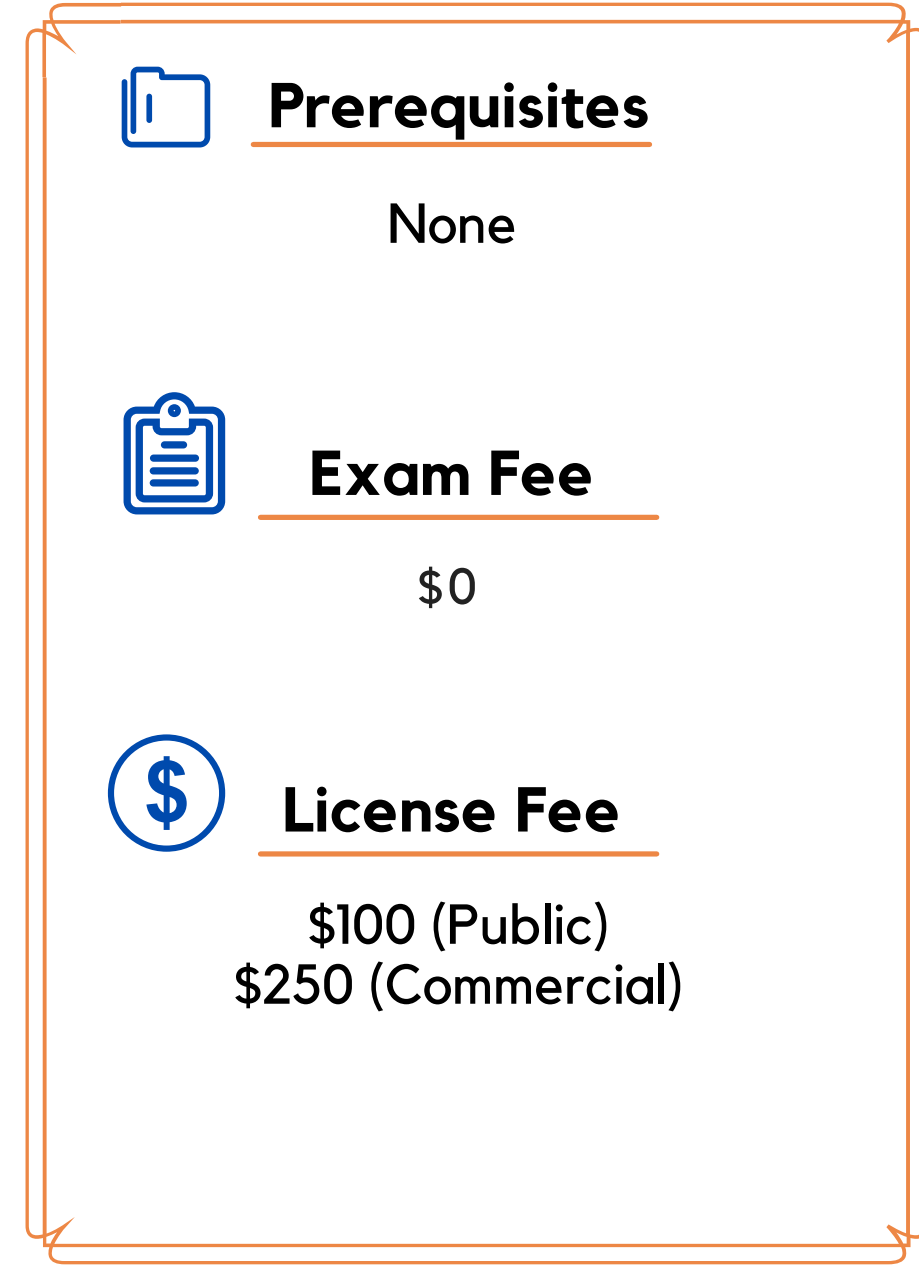

\section{Study Material}

Applying Pesticides

SM 1 Correctly

WWW.IFASBOOKS.COM

Agricultural Row Crop SM 5 Pest Control

WWW.IFASBOOKS.COM

\section{Exam Information}

- Ag Row exam AND General Standards (CORE) Exam

- 50 questions each, multiple-choice

- 2 hours per exam

- Must pass with 70\%

Schedule your exam at https://pesticideexam.ifas.ufl.edu 


\section{Agricultural Row Crop}

RENEWAL INFORMATION

(1) Renewal Period

4 years

\$) Renewal Fee

$\$ 100$ (Public)

$\$ 250$ (Commercial)

Late Fee After License

$\$$ Expires and Grace

Period is Over

$\$ 50$
总 CEU Renewal Requirements

4 CORE 487

8 Ag Row
Grace Period After

(i) License Expires

- 365 days to renew

- Late fee charged 60 days after license expiration

\section{\$ Paying Your Renewal}

You can pay your renewal and upload your documents at https://aesecomm.fdacs.gov 


\section{Agricultural Tree Crop}

- Applications to production trees; includes citrus, blueberries, pecans, or crop grown on woody shrubs/trees. Use of RUP fumigants requires "Soil and Greenhouse Fumigation" license.

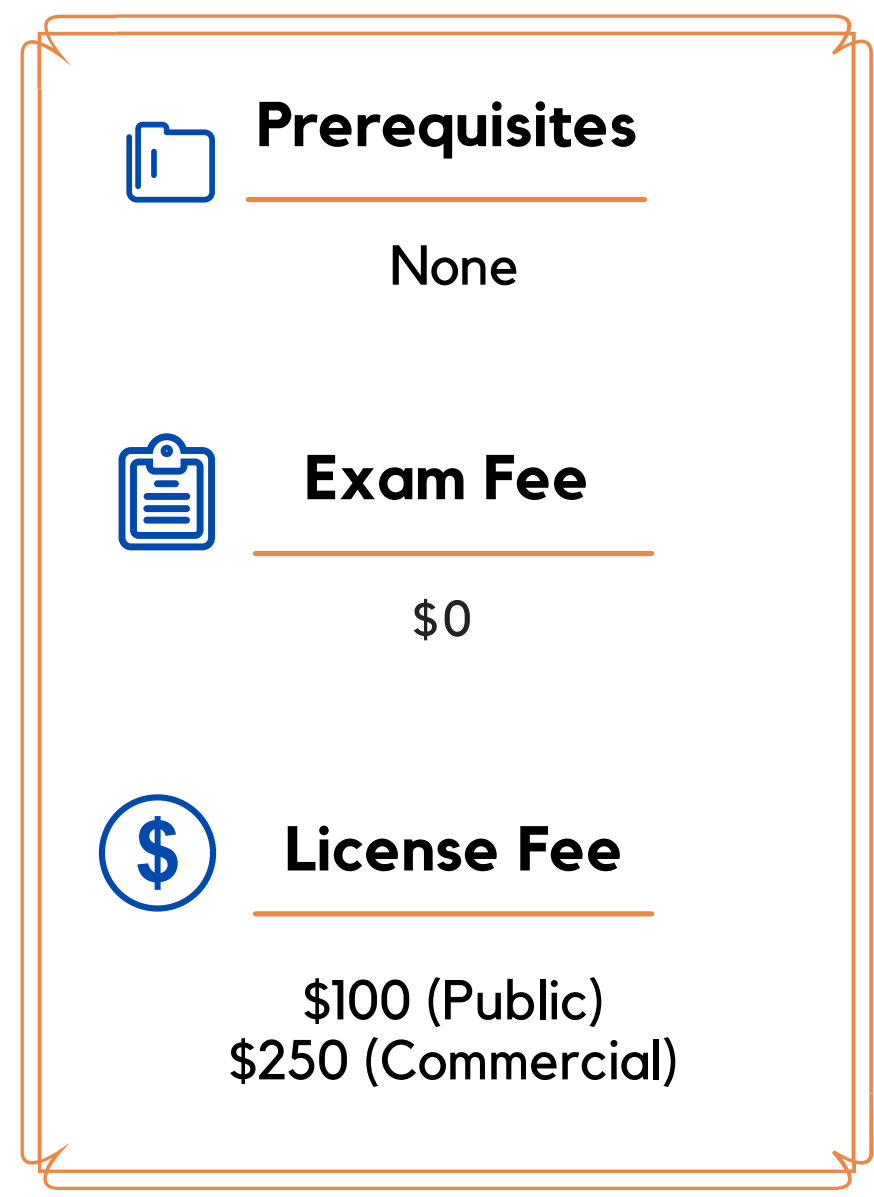

\section{Study Material}

\section{Applying Pesticides \\ Correctly \\ SM 1}

WWW.IFASBOOKS.COM

\section{Agricultural Tree Crop SM 63 Pest Control}

\section{洋 Exam Information}

- Ag Tree Exam AND General Standards (CORE) Exam

- 50 questions each, multiple-choice

- 2 hours per exam

- Must pass with $70 \%$

Schedule your exam at https://pesticideexam.ifas.ufl.edu 


\section{Agricultural Tree Crop}

RENEWAL INFORMATION

\section{(1) Renewal Period}

4 years

\section{\$) Renewal Fee \\ $\$ 100$ (Public) \\ $\$ 250$ (Commercial)}

Late Fee After License

(\$) Expires and Grace Period is Over

$\$ 50$
送 $\begin{aligned} & \text { CEU Renewal } \\ & \text { Requirements }\end{aligned}$
4 CORE 487
$8 \mathrm{Ag}$ Tree

\section{Grace Period After} License Expires

- 365 days to renew

- Late fee charged 60 days after license expiration

\$ Paying Your Renewal

You can pay your renewal and upload your documents at https://aesecomm.fdacs.gov 


\section{Seed Treatment}

- For the treatment of seeds that are intended for planting. This includes treatment to seeds stored for later planting. NOT for use on seeds that are food or feed. Use of RUP fumigants requires "Soil and Greenhouse Fumigation" license.

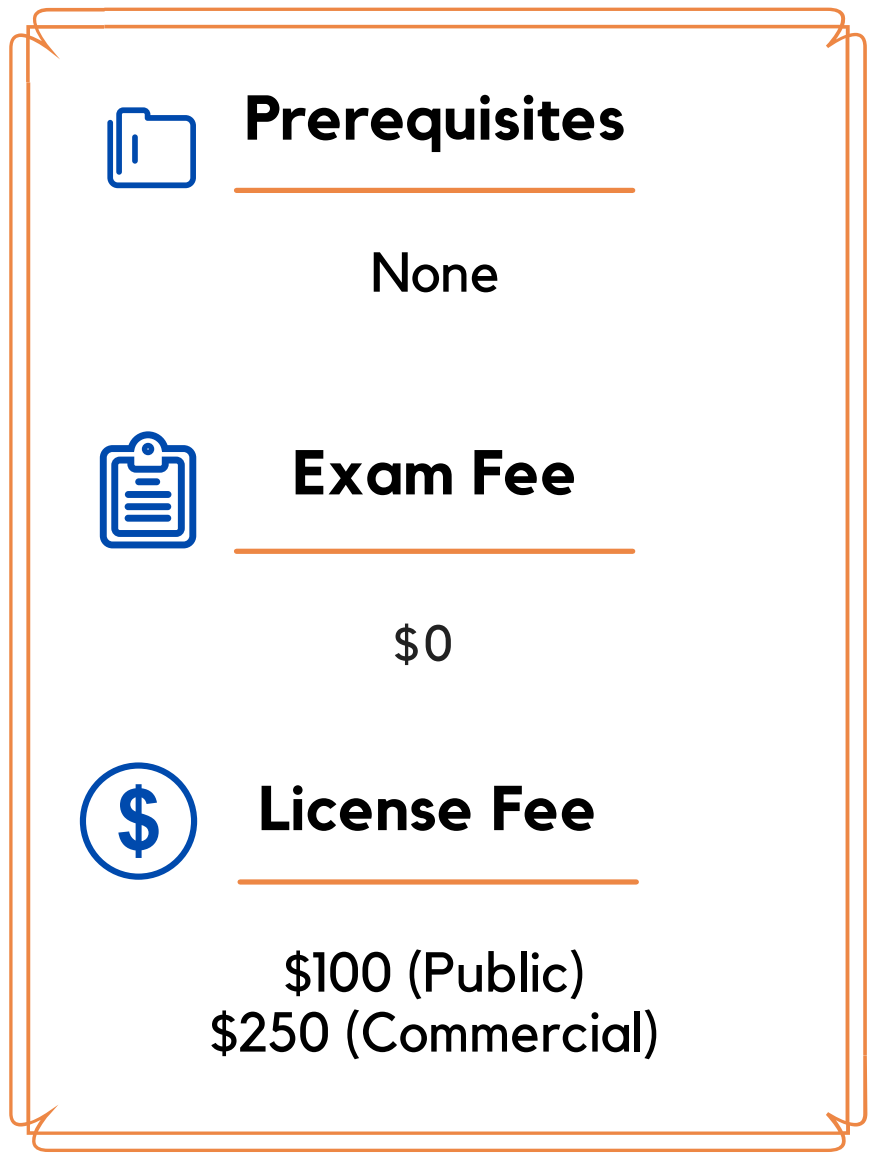

\section{Study Material}

\section{Applying Pesticides SM 1 Correctly}

WWW.IFASBOOKS.COM

Seed Treatment a Guide for

Commercial Applicators

PESTICIDE INFORMATION OFFICE

\section{涼 Exam Information}

- Seed Treatment exam AND General Standards (CORE) Exam

- 50 questions each, multiple-choice

- 2 hours per exam

- Must pass with $70 \%$

Schedule your exam at https://pesticideexam.ifas.ufl.edu 


\section{Seed Treatment}

\section{RENEWAL INFORMATION}

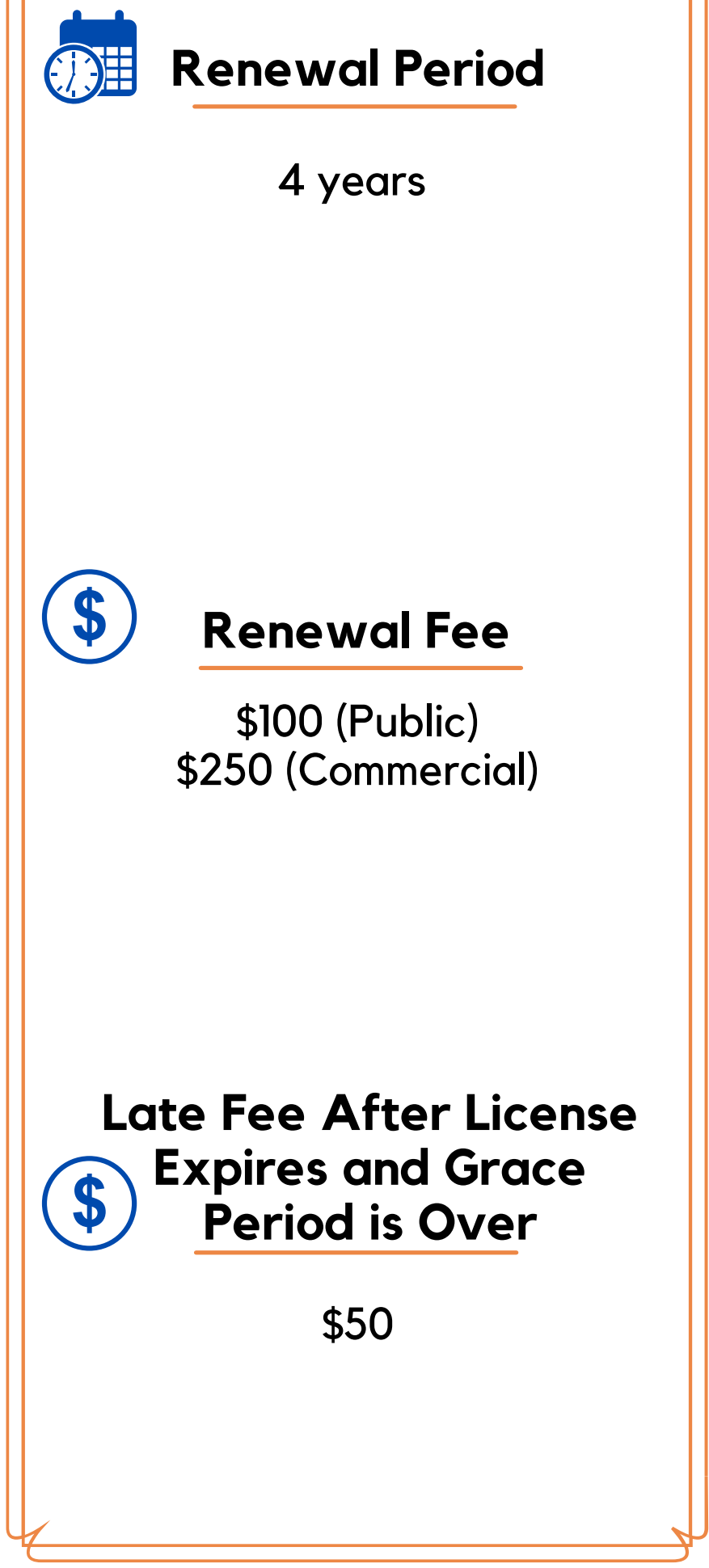

递 CEU Renewal

4 CORE 487

4 Seed Treatment

\section{Grace Period After (1) License Expires}

- 365 days to renew

- Late fee charged 60 days after license expiration

\$) Paying Your Renewal

You can pay your renewal and upload your documents at https://aesecomm.fdacs.gov 


\section{Soil and Greenhouse} Fumigation

- Fumigant injections or applications to field soils, containerized plants, potting soil, lawns, turf, and ornamentals not associated with structures; or within enclosed agricultural structures such as greenhouses where agricultural production is in progress.

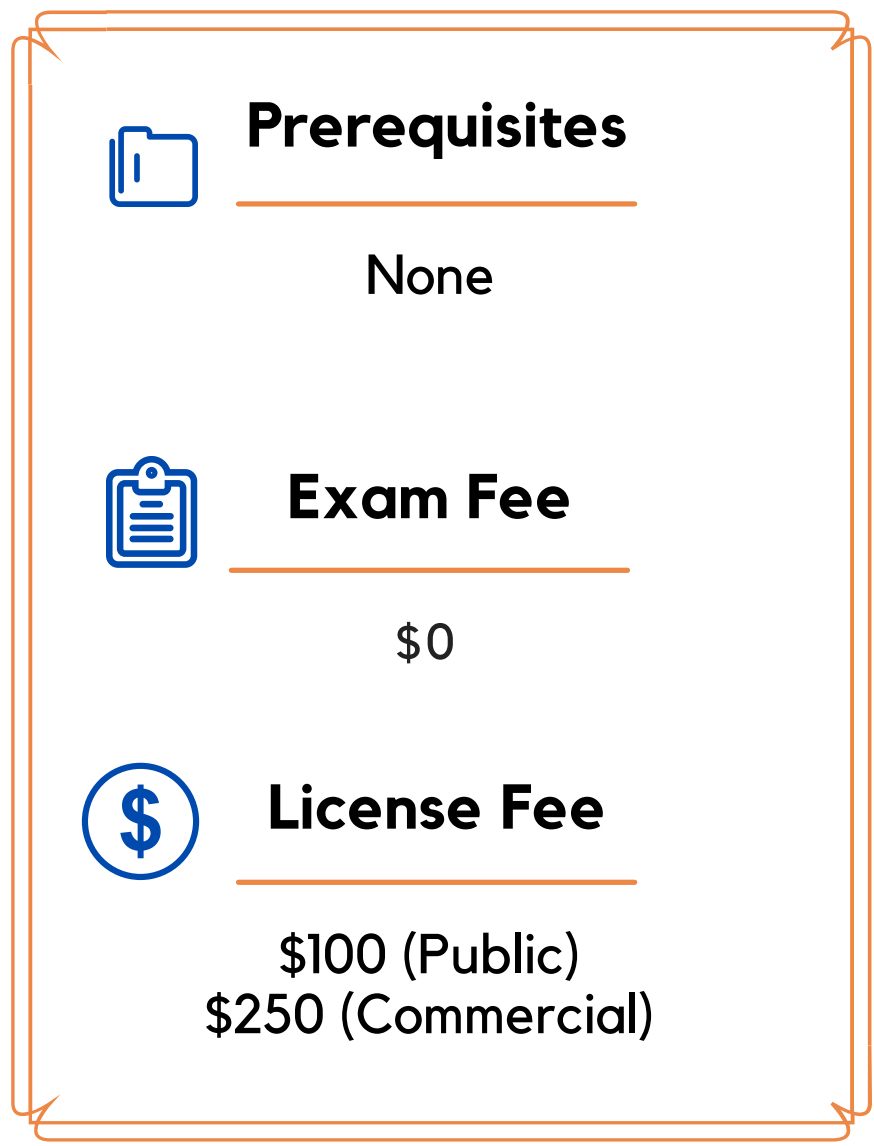

\section{Study Material}

Applying Pesticides

SM 1

Correctly

WWW.IFASBOOKS.COM

Soil Fumigation

SM 61

WWW.IFASBOOKS.COM

\section{河 Exam Information}

- Soil Greenhouse Fumigation exam AND General Standards (CORE) Exam

- 50 questions each, multiple-choice

- 2 hours per exam

- Must pass with $70 \%$

Schedule your exam at https://pesticideexam.ifas.ufl.edu 


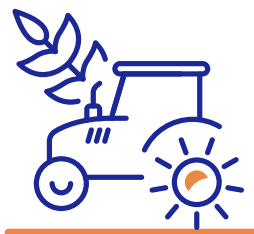

\section{Soil and Greenhouse \\ Fumigation}

\section{RENEWAL INFORMATION}

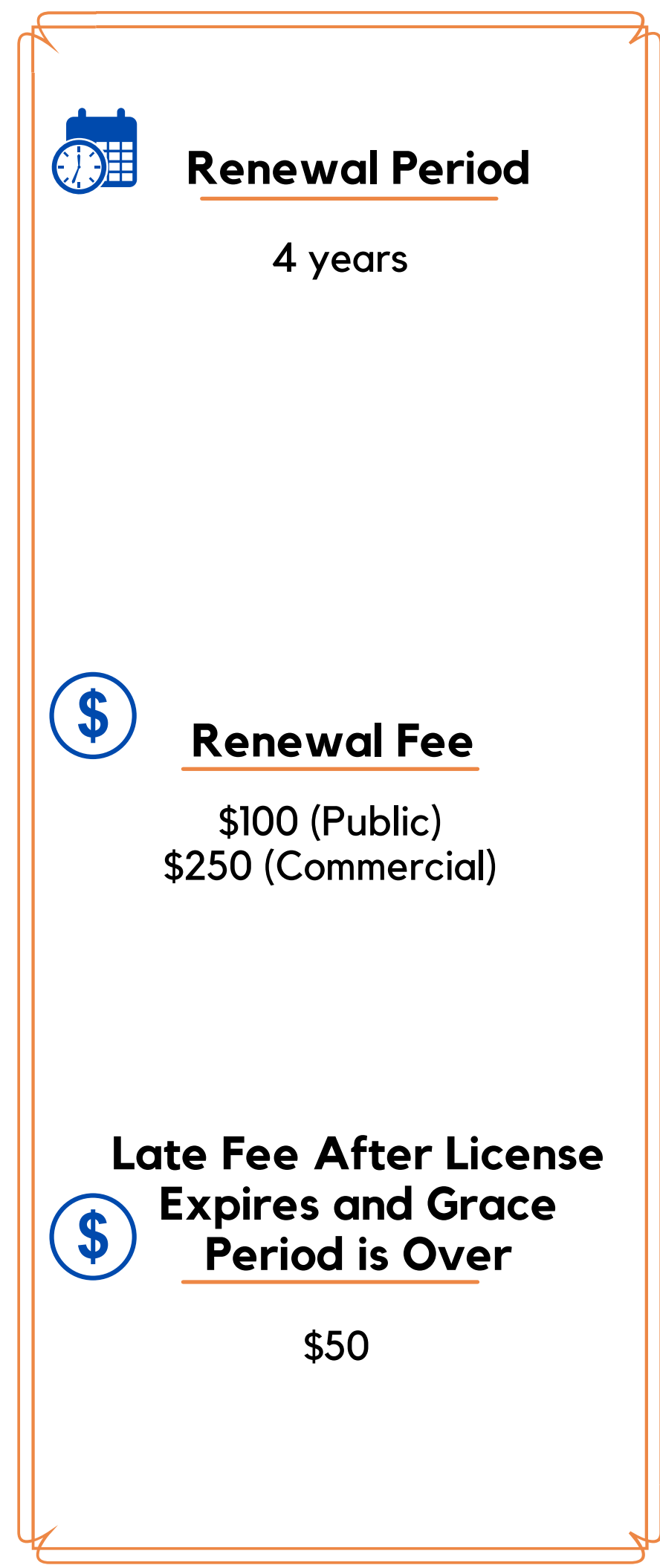

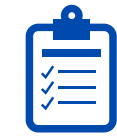

CEU Renewal

Requirements

4 CORE 487

4 Soil and Greenhouse Fumigation

\section{Grace Period After \\ (i) License Expires}

- 365 days to renew

- Late fee charged 60 days after license expiration

\section{\$) Paying Your Renewal}

You can pay your renewal and upload your documents at https://aesecomm.fdacs.gov 


\section{Raw Agricultural Commodity Fumigation}

- Fumigant injection or application to any postharvest raw agricultural commodity in a storage facility or during processing or manufacturing procedures; or applied to or within a storage facility before or after the facility received the raw agricultural commodity for storage. Storage facilities include but are not limited to corn cribs, grain elevators, tobacco barns, produce trailers, farm vehicles used to store agricultural commodities, processing plant bins or storage rooms for raw commodities, and any other enclosed structure used to contain a harvested raw agricultural commodity.

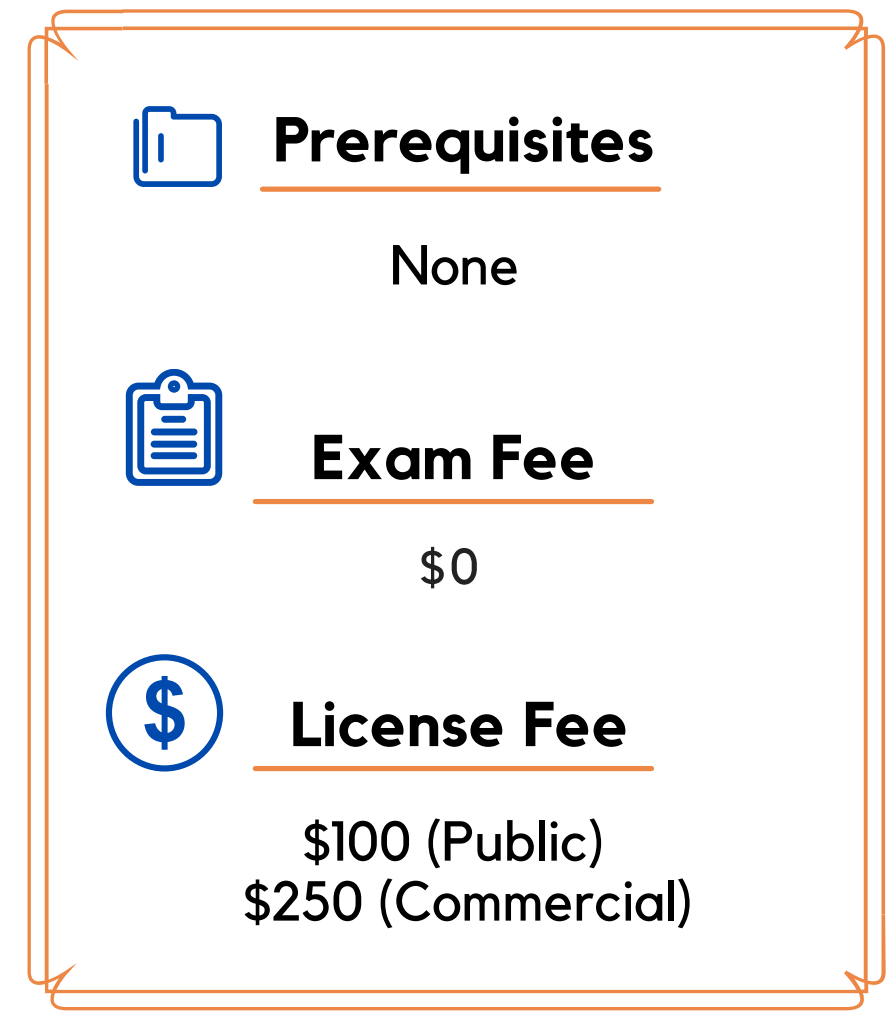

\section{Study Material}

Applying Pesticides $\quad$ SM 1
Correctly

WWW.IFASBOOKS.COM

Raw Agricultural

SM 66

Commodity Fumigation

WWW.IFASBOOKS.COM

\section{泣 Exam Information}

- Raw Ag Fumigation exam AND General Standards (CORE) Exam

- 50 questions each, multiple-choice

- 2 hours per exam

- Must pass with $70 \%$

Schedule your exam at https://pesticideexam.ifas.ufl.edu 


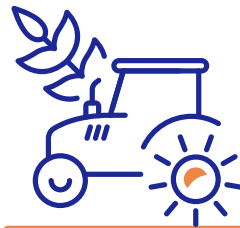

\section{Raw Agricultural \\ Commodity Fumigation}

\section{RENEWAL INFORMATION}

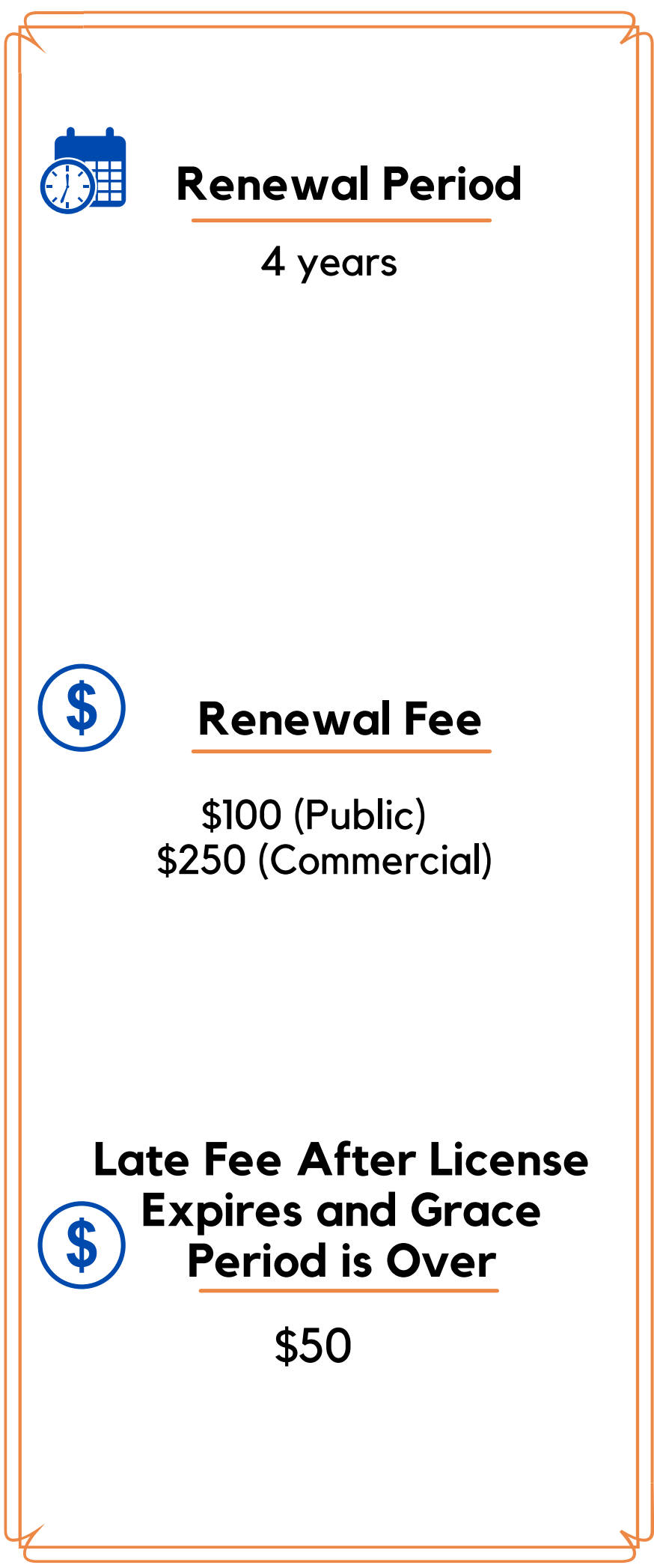

\section{CEU Renewal \\ Requirements}

4 CORE 487

4 Raw Ag Commodity Fumigation

\section{.}

\section{Grace Period After} License Expires

- 365 days to renew

- Late fee charged 60 days after license expiration

(\$) Paying Your Renewal

You can pay your renewal and upload your documents at https://aesecomm.fdacs.gov 


\section{Aerial}

11 Prerequisites

Pilot's license

\$) License Fee $\$ 250$ (Commercial)

\section{Study Material}

Applying Pesticides

SM 1 Correctly

WWW.IFASBOOKS.COM

Aerial Application

SM 41
WWW.IFASBOOKS.COM

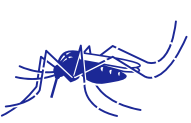

Any aerial applications for mosquito control MUST also have a Public Health Applicators License.

\section{Exam Information}

- Aerial exam AND General Standards (CORE) Exam

- 50 questions each, multiple-choice

- 2 hours per exam

- Must pass with $70 \%$

Schedule your exam at https://pesticideexam.ifas.ufl.edu 


\section{Aerial}

\section{RENEWAL INFORMATION}

\section{(1) Renewal Period}

4 years

(\$) Renewal Fee

$\$ 100$ (Public)

$\$ 250$ (Commercial)

Late Fee After License

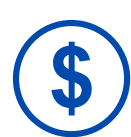
Expires and Grace Period is Over

$\$ 50$
送 CEU Renewal

4 CORE 487

16 Aerial

\section{Grace Period After}

调

\section{License Expires}

- 365 days to renew

- Late fee charged 60 days after license expiration

\section{(\$) Paying Your Renewal}

You can pay your renewal and upload your documents at https://aesecomm.fdacs.gov 


\section{Agricultural Animal}

- Applications directly to animals, or in/on places where animals are kept or confined (includes swine, cattle, sheep, horses, fish, poultry, bees, and other agricultural livestock).

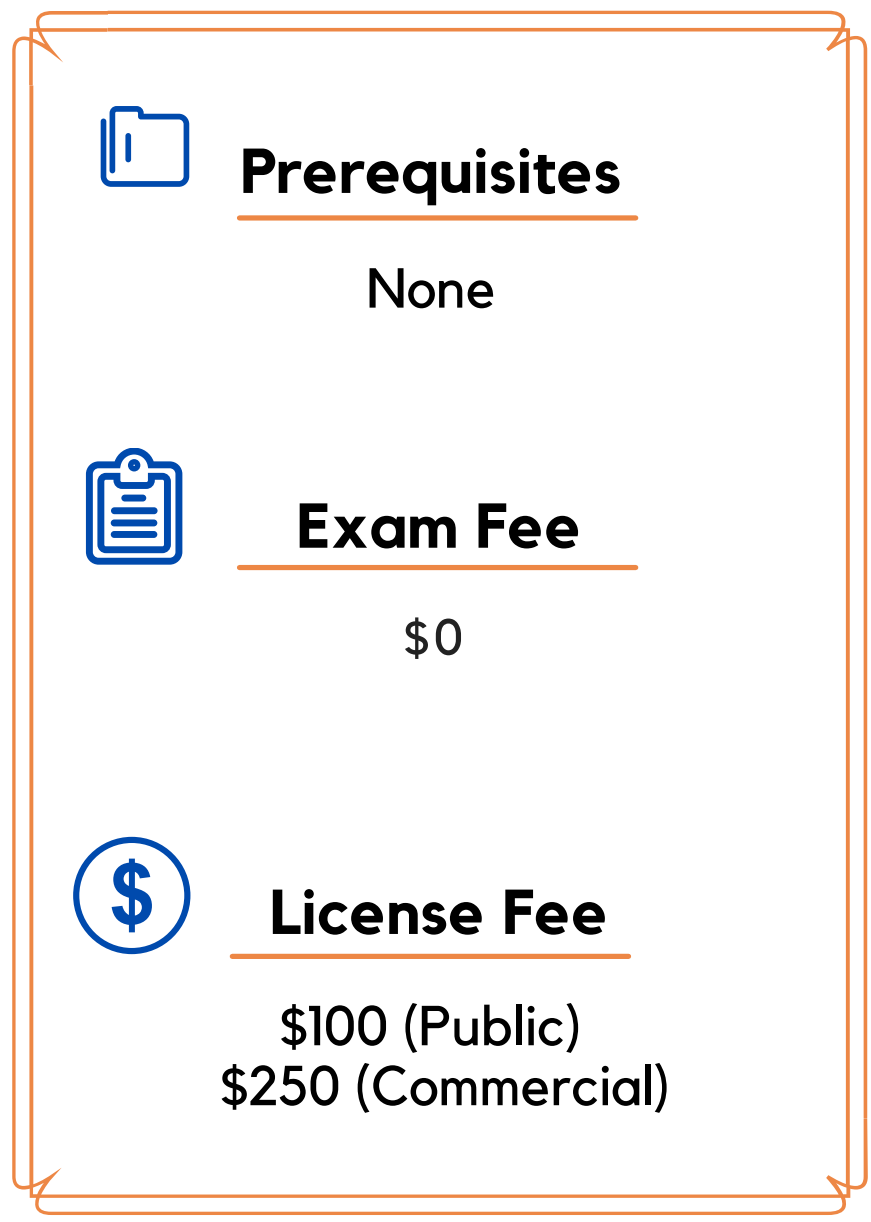

Applying Pesticides Correctly

\section{Study Material}

Agricultural Pest

SM 2

Control: Animals

WWW.IFASBOOKS.COM

SM 1

WWW.IFASBOOKS.COM

\section{漫 Exam Information}

- Ag Animal Exam AND General Standards (CORE) Exam

- 50 questions each, multiple-choice

- 2 hours per exam

- Must pass with $70 \%$

Schedule your exam at https://pesticideexam.ifas.ufl.edu 


\section{Agricultural Animal}

RENEWAL INFORMATION

\section{(1) Renewal Period}

4 years

\section{\$) Renewal Fee \\ $\$ 100$ (Public) \\ $\$ 250$ (Commercial)}

Late Fee After License

(\$) Expires and Grace

\$ Period is Over

$\$ 50$
送 CEU Renewal

4 CORE

4 Agricultural Animal
Grace Period After License Expires

- 365 days to renew

- Late fee charged 60 days after license expiration

\section{\$) Paying Your Renewal}

You can pay your renewal and upload your documents at https://aesecomm.fdacs.gov 
- Use of pesticides in forests for production of timber/pulp, forest nurseries, or forest seed orchards. Use of RUP fumigants requires "Soil and Greenhouse Fumigation" license.

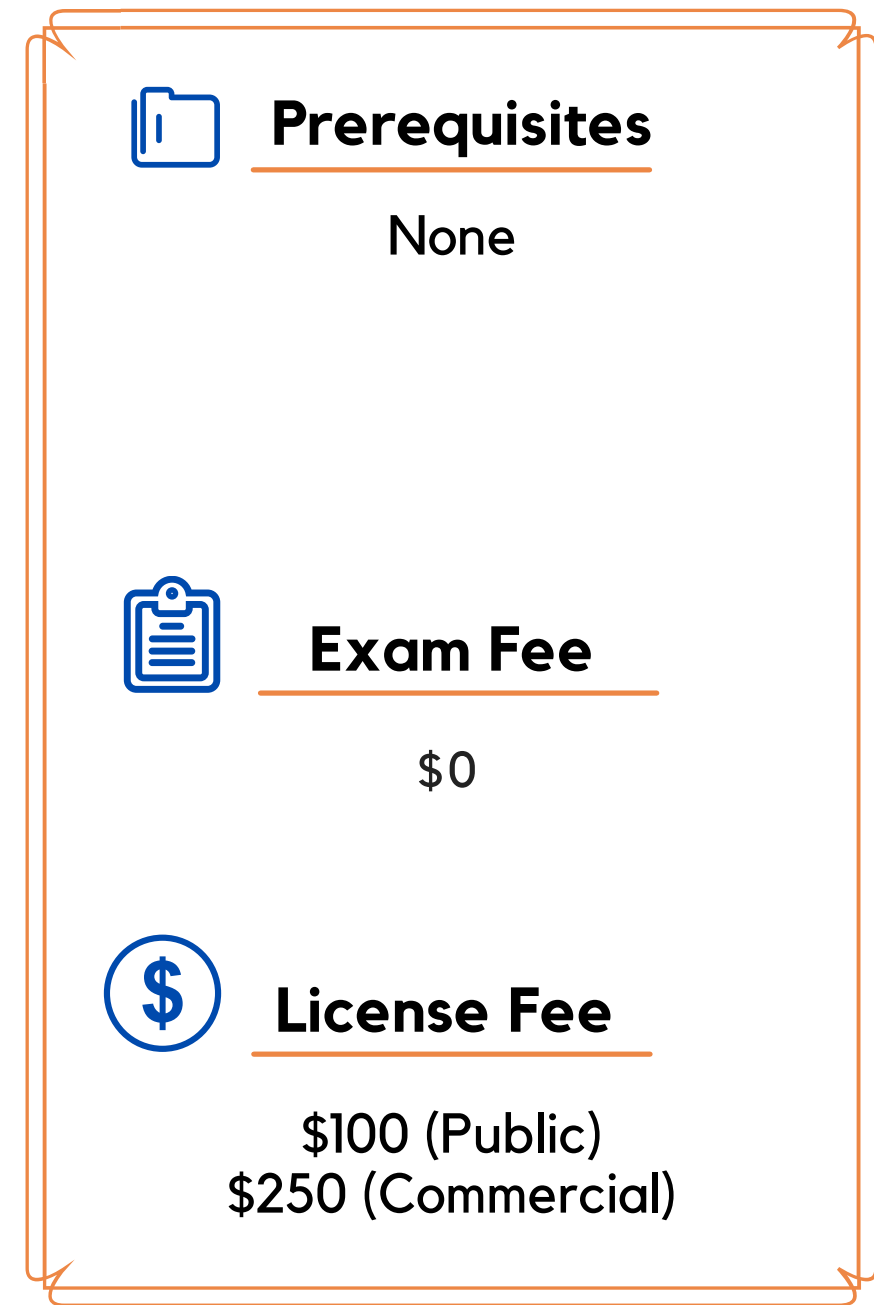

\section{Study Material}

Applying Pesticides Correctly

WWW.IFASBOOKS.COM

Forest Pest Control

SM 43

SM 1

\section{Correctly}

WWW.IFASBOOKS.COM

\section{湷 Exam Information}

- Forest Pest Exam AND General Standards (CORE) Exam

- 50 questions each, multiple-choice

- 2 hours per exam

- Must pass with 70\%

Schedule your exam at https://pesticideexam.ifas.ufl.edu 


\section{Forest}

\section{RENEWAL INFORMATION}

\section{(1) Renewal Period}

4 years

\$ Renewal Fee $\$ 0$
Late Fee After License (\$) Expires and Grace Period is Over

\section{를 CEU Renewal Requirements}

4 CORE

8 Forest Pest Control

\section{Grace Period After License Expires}

- 365 days to renew

- Late fee charged 60 days after license expiration
(\$) Paying Your Renewal

You can pay your renewal and upload your documents at https://aesecomm.fdacs.gov 


\section{Ornamental and Turfgrass}

- Production of ornamental trees, shrubs, flowers, or sod. Maintenance of ornamental trees, shrubs, and plants, or sod and turfgrass growing in or on cemeteries, golf courses, parks, or athletic fields. Does NOT include lawns or ornamental species around structures. On these sites, the use of RUP fumigants requires a "Soil and Greenhouse Fumigation" license.

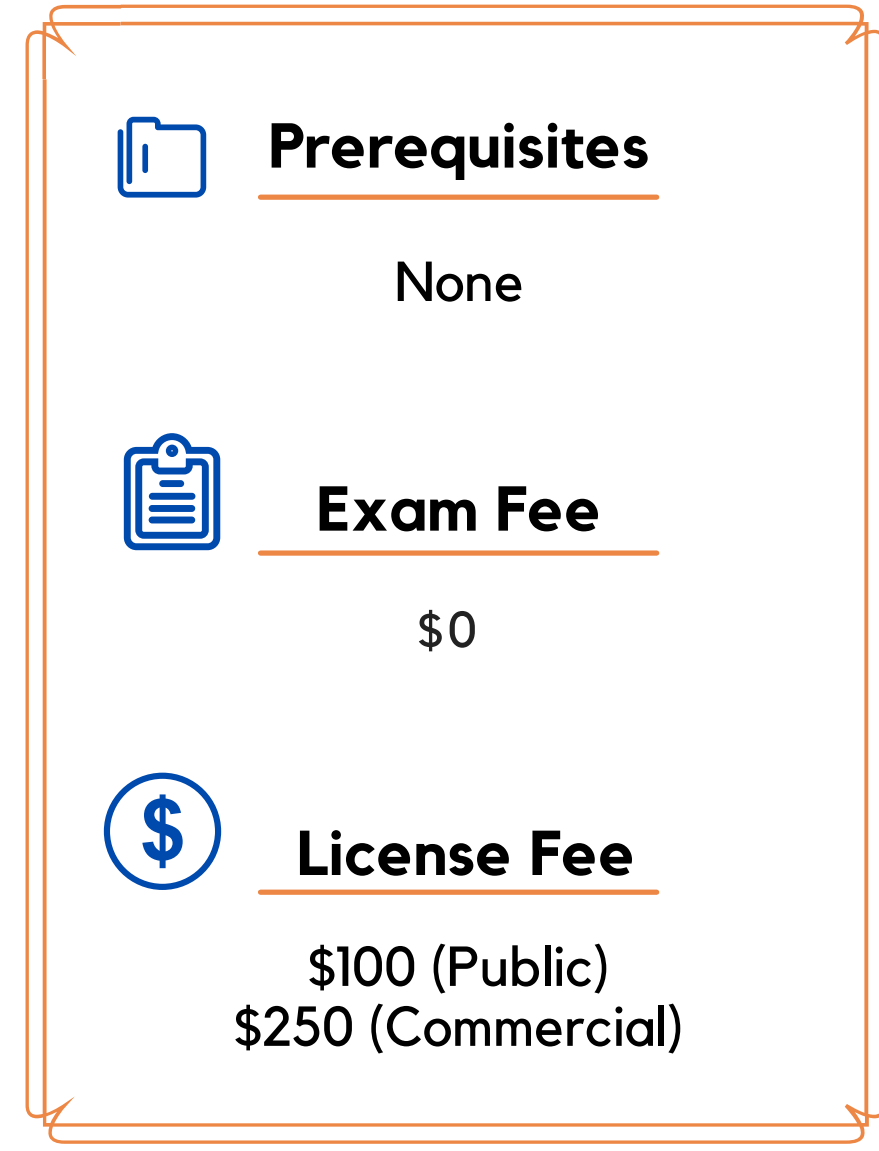

WWW.IFASBOOKS.COM

Applying Pesticides

SM 1

Correctly

Study Material

Ornamental and

SM 7

Turfgrass Pest

Management

WWW.IFASBOOKS.COM

\section{泣 Exam Information}

- Ornamental and Turf exam AND General Standards (CORE) Exam

- 50 questions each, multiple-choice

- 2 hours per exam

- Must pass with $70 \%$

Schedule your exam at https://pesticideexam.ifas.ufl.edu 


\section{RENEWAL INFORMATION}

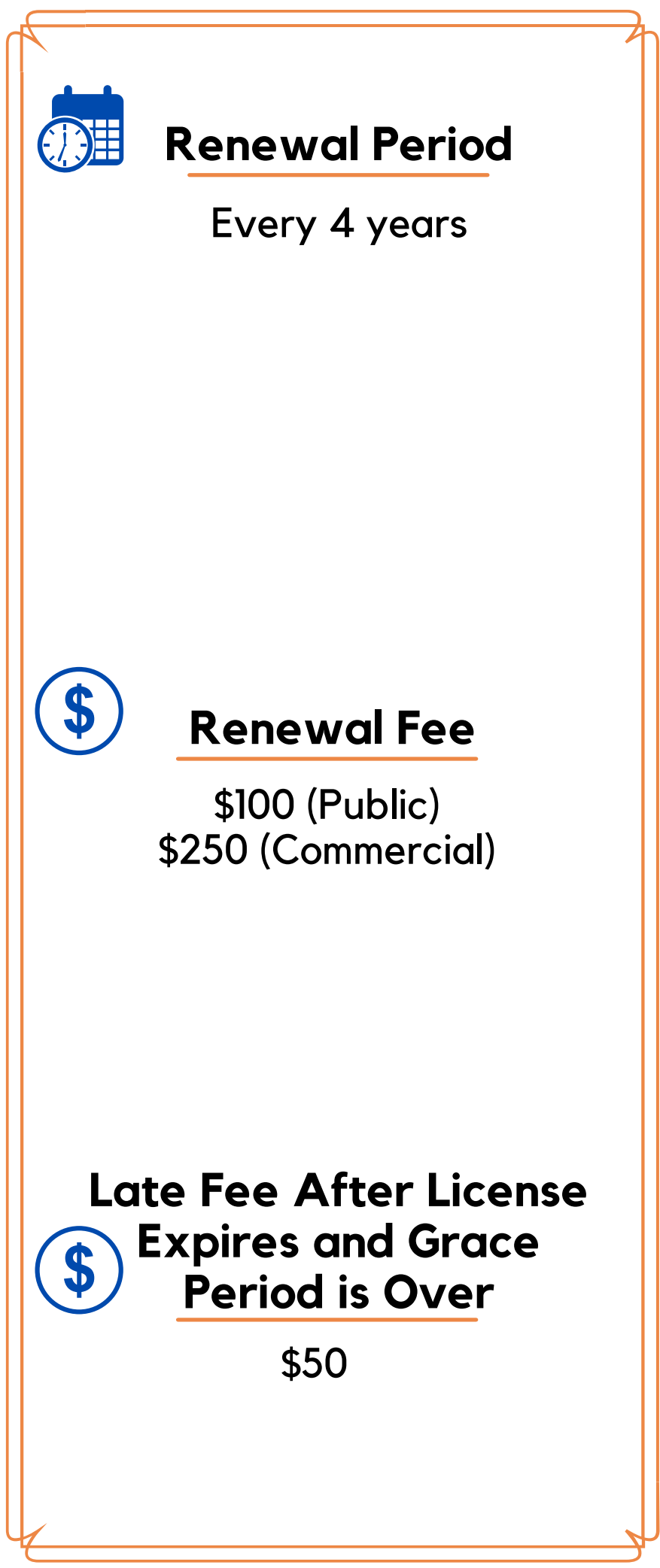

圈

CEU Renewal

Requirements

4 CORE 487

12 Ornamental \& Turfgrass

\section{Grace Period After}

(i) License Expires

- 365 days to renew

- Late fee charged 60 days after license expiration
(\$) Paying Your Renewal

You can pay your renewal and upload your documents at https://aesecomm.fdacs.gov 


\section{Natural Areas}

- Management of unwanted vegetation to protect natural communities of conservation and recreation lands and other natural areas.

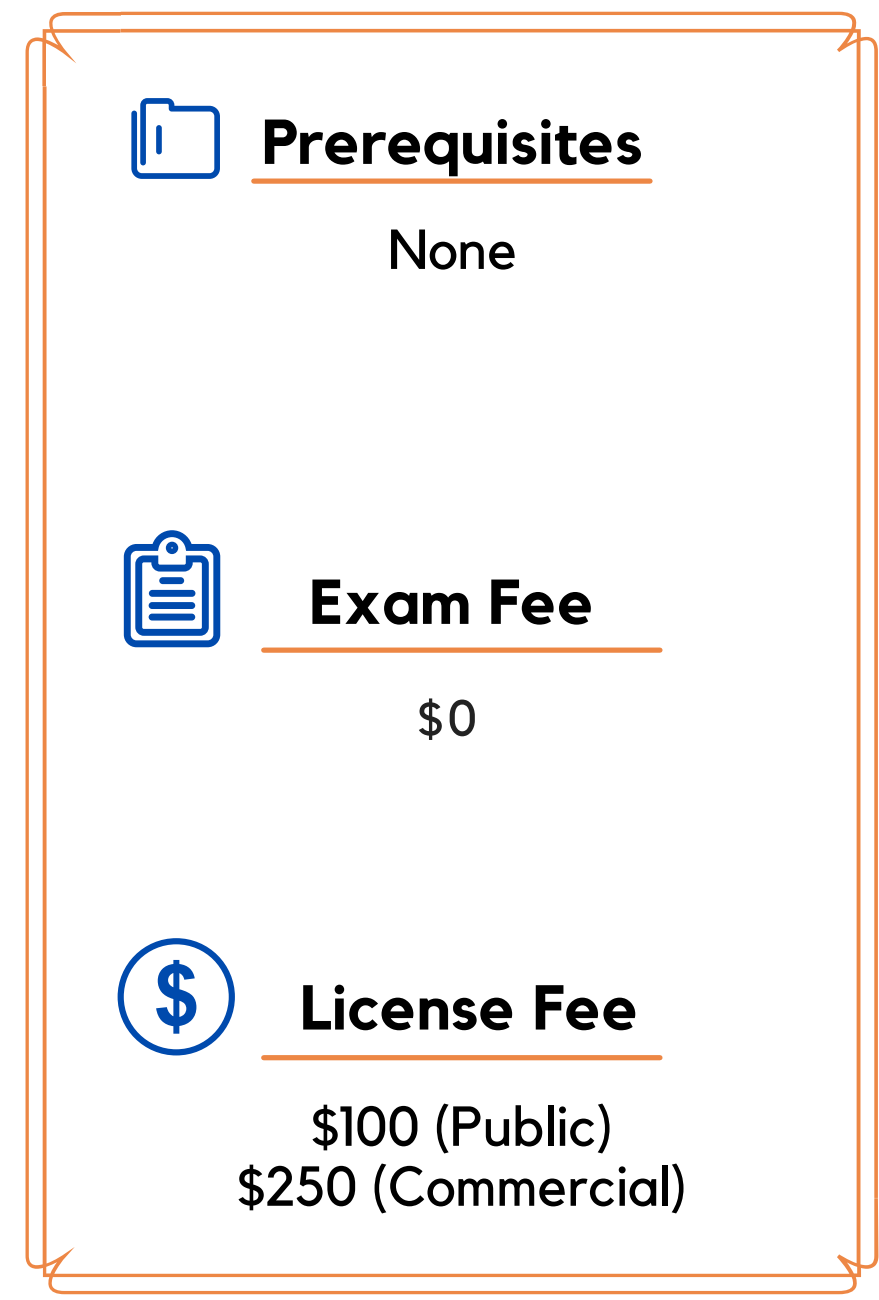

Natural Areas Weed SP 295 Management

\section{Study Material}

Applying Pesticides
Correctly

WWW.IFASBOOKS.COM

WWW.IFASBOOKS.COM

\section{泣 Exam Information}

- Natural Areas Exam AND General Standards (CORE) Exam

- 50 questions each, multiple-choice

- 2 hours per exam

- Must pass with $70 \%$

Schedule your exam at https://pesticideexam.ifas.ufl.edu 


\section{Natural Areas}

\section{RENEWAL INFORMATION}

\section{(1) Renewal Period}

Every 4 years

\$ Renewal Fee

$\$ 100$ (Public) $\$ 250$ (Commercial)

Late Fee After License (\$) Expires and Grace Period is Over $\$ 50$
CEU Renewal
Requirements

4 CORE 487

16 Natural Area

\section{Grace Period After}

(1) License Expires

- 365 Days to Renew

- Late fee charged 60 days after license expiration

\section{$\$$}

Paying Your Renewal

You can pay your renewal and upload your documents at https://aesecomm.fdacs.gov 


\section{Aquatic}

- Applications to water, standing or running water, banks or shorelines. Those performing chlorine gas injections or treating for public health purposes should refer to those respective categories.

11 Prerequisites

None

Exam Fee $\$ 0$

(\$)

License Fee

$\$ 100$ (Public) $\$ 250$ (Commercial)

\section{Study Material}

\section{Applying Pesticides Correctly}

WWW.IFASBOOKS.COM

Aquatic Pest Control SM 3

WWW.IFASBOOKS.COM

\section{泣 Exam Information}

- Aquatics exam AND General Standards (CORE) Exam

- 50 questions each, multiple-choice

- 2 hours per exam

- Must pass with $70 \%$

Schedule your exam at https://pesticideexam.ifas.ufl.edu 


\section{Aquatic}

\section{RENEWAL INFORMATION}

\section{(1) Renewal Period}

Every 4 years
圈

CEU Renewal

Requirements

4 CORE 487

16 Aquatic

\section{(\$) Renewal Fee \\ $\$ 100$ (Public) $\$ 250$ (Commercial)}

Late Fee After License (\$) Expires and Grace $\$$ Period is Over $\$ 50$
\$) Grace Period After (1) License Expires

- 365 days to renew

- Late fee charged 60 days after license expiration
You can pay your renewal and upload your documents at https://aesecomm.fdacs.gov 


\section{Right of Way}

- Maintenance of right-of-way areas associated with public roads, electric power lines, pipelines, railroads, and other similar areas. Use of RUP fumigants requires "Soil and Greenhouse Fumigation" license.

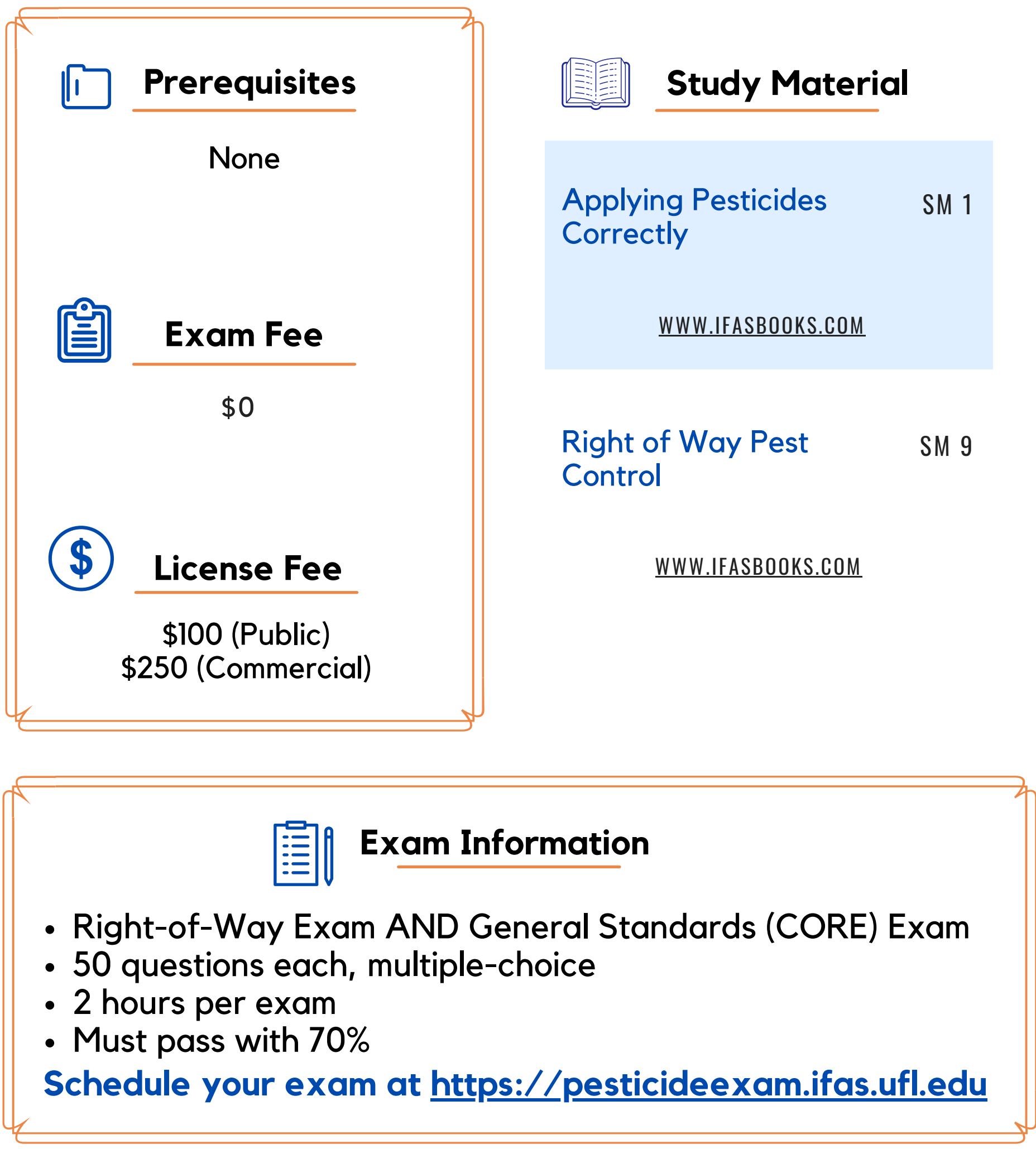




\section{Right of Way}

\section{RENEWAL INFORMATION}

\section{(1) Renewal Period}

Every 4 years

\$) Renewal Fee

$\$ 100$ (Public) $\$ 250$ (Commercial)
Late Fee After License

\$ Expires and Grace Period is Over $\$ 50$
CEU Renewal

送 Requirements

4 CORE 487

8 ROW

\section{Grace Period After} License Expires

- 365 days to renew

- Late fee charged 60 days after license expiration

\section{(\$) Paying Your Renewal}

You can pay your renewal and upload your documents at https://aesecomm.fdacs.gov 


\section{Wood Treatment}

- For the use of wood preservative or other treatment products at wood treatment facilities to produce "treated wood." Use of RUP fumigants requires "Soil and Greenhouse Fumigation" license.

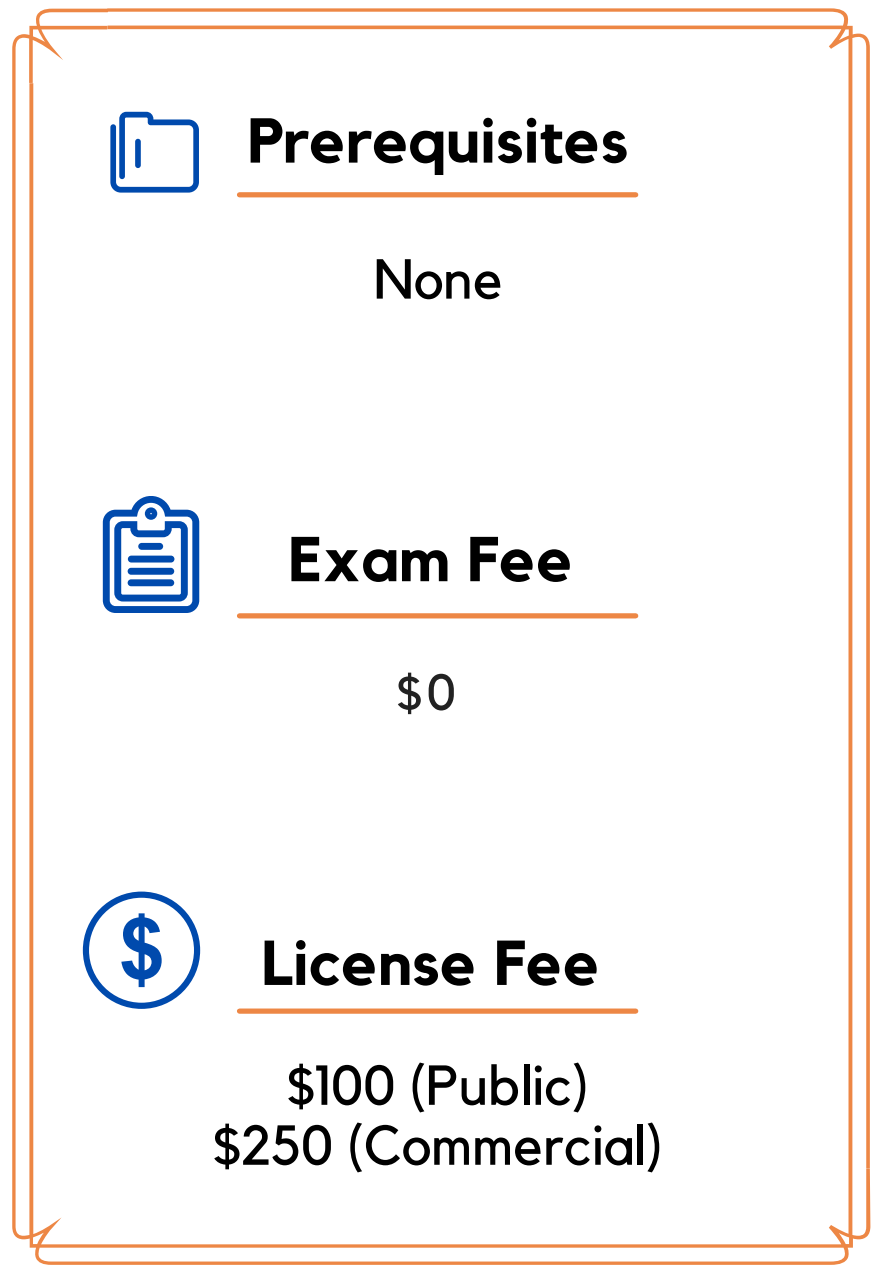

\section{Study Material}

Applying Pesticides

Correctly

\section{湔 Exam Information}

- Wood Treatment exam AND General Standards (CORE) Exam

- 50 questions each, multiple-choice

- 2 hours per exam

- Must pass with $70 \%$

Schedule your exam at https://pesticideexam.ifas.ufl.edu 


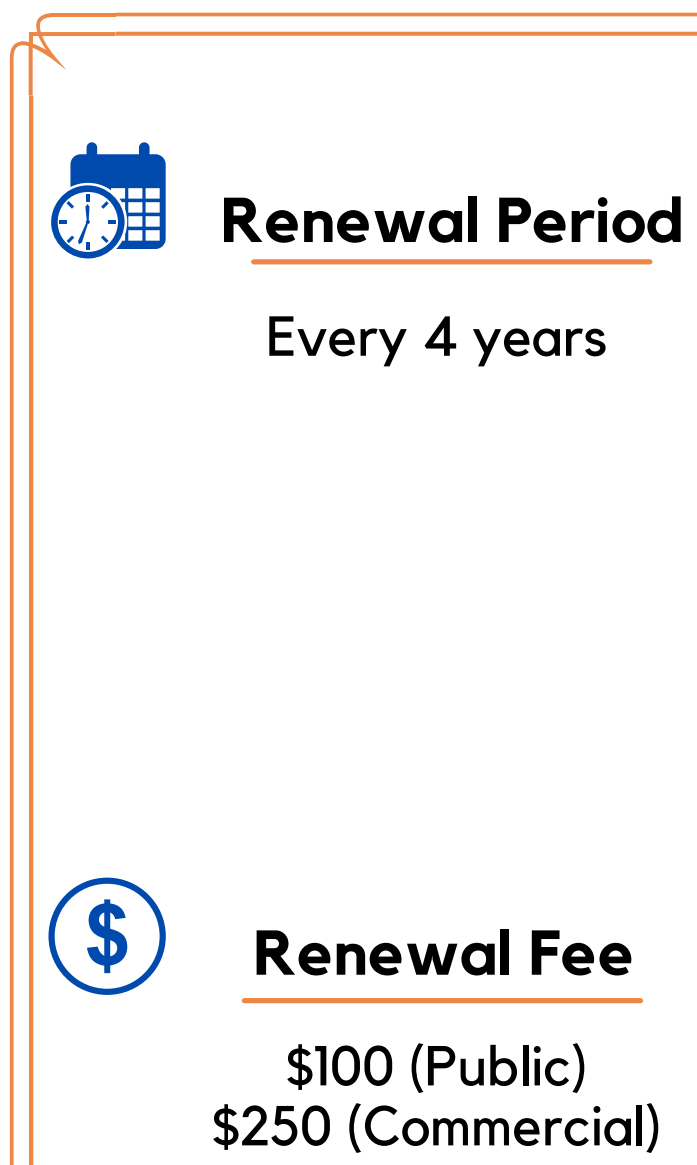

Late Fee After License (\$) Expires and Grace Period is Over $\$ 50$

\section{CEU Renewal Requirements}

4 CORE 487

4 Wood Treatment
Grace Period After (i) License Expires

- 365 days to renew

- Late fee charged 60 days after license expiration
\$) Paying Your Renewal

You can pay your renewal and upload your documents at https://aesecomm.fdacs.gov 


\section{Organotin Antifouling Paint}

- Applications of organotin antifouling paint or other products applied to submerged portions of aquatic and marine structures and vessels to prevent the growth of aquatic or marine organisms.

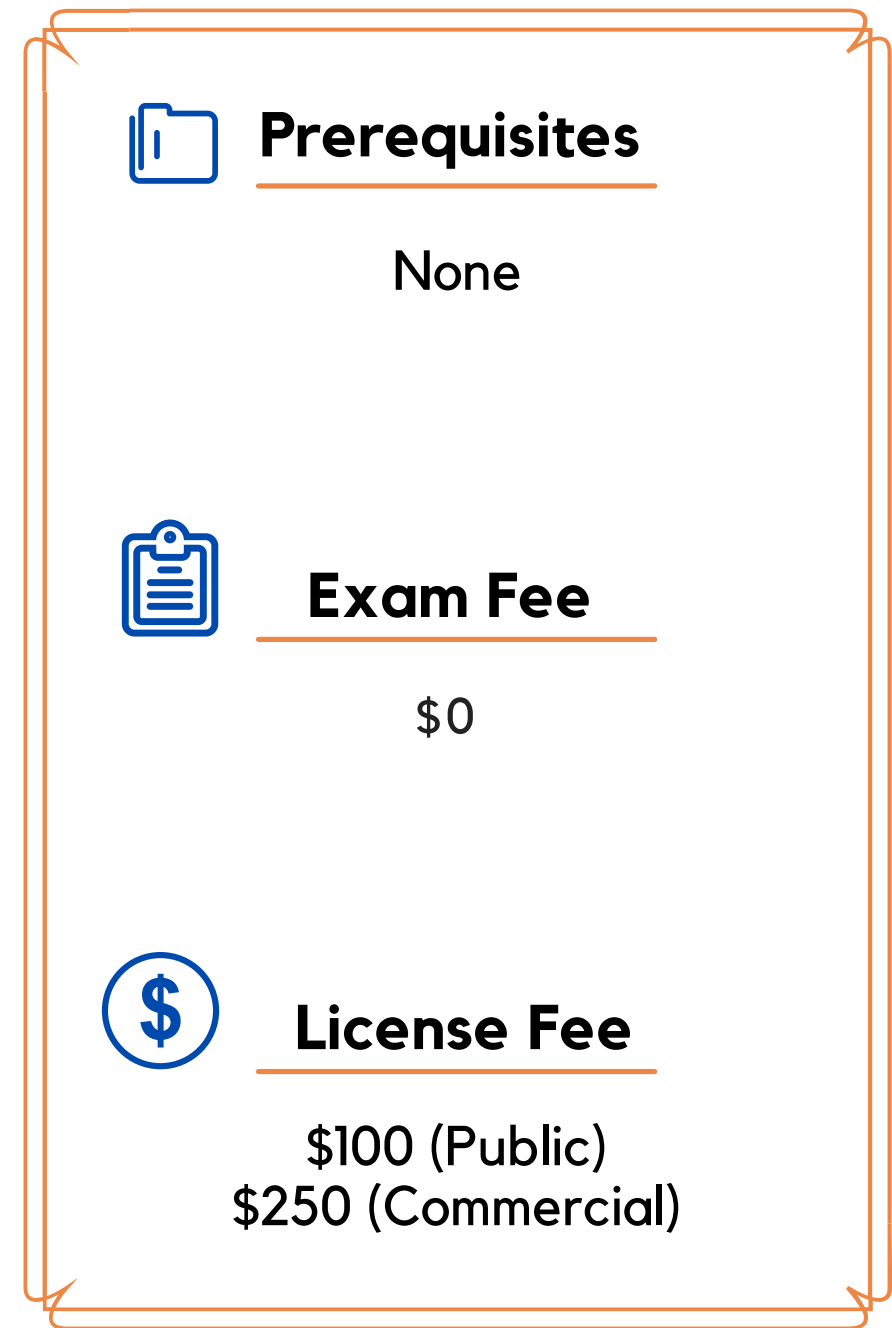

\section{Antifouling Paint Pest Control}

WWW.IFASBOOKS.COM

\section{Study Material}

\section{渒腈 Exam Information}

- Organotin Antifouling Exam

- 50 questions, multiple-choice

- 2 hours per exam

- Must pass with $70 \%$

Schedule your exam at https://pesticideexam.ifas.ufl.edu 


\section{Organotin Antifouling Paint}

RENEWAL INFORMATION

\section{(1) Renewal Period}

Every 4 years

\$) Renewal Fee

$\$ 100$ (Public) $\$ 250$ (Commercial)

\section{Late Fee After License}

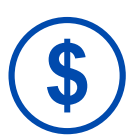

Expires and Grace

Period is Over

$\$ 50$
送 CEU Renewal

4 CORE 487 *

4 Antifouling

*CORE CEUs are required; however,

no CORE exam is required.

\section{Grace Period After}

讨用 License Expires

- 365 days to renew

- Late fee charged 60 days after license expiration

\section{(\$) Paying Your Renewal}

You can pay your renewal and upload your documents at https://aesecomm.fdacs.gov 


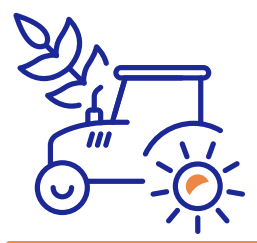

\section{Sewer Root}

- For the prevention of root growth in sewer lines or pipes.

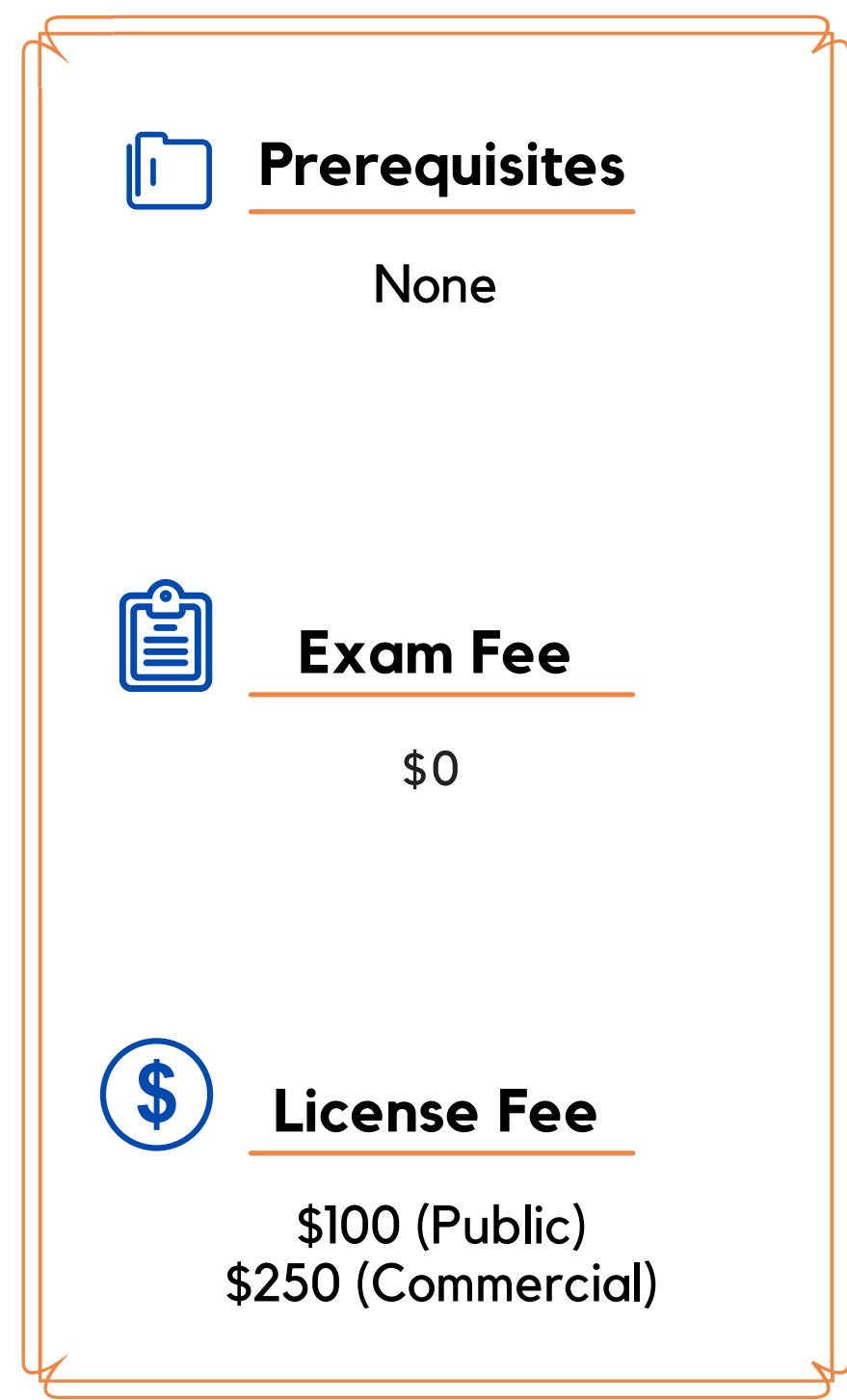

Study Material

Sewer Root Control

Training Manual

CALL FDACS AT (850)617-7870

\section{易 Exam Information}

- Sewer root exam

- 60 questions, multiple-choice

- 2 hours per exam

- Must pass with $70 \%$

Schedule your exam at https://pesticideexam.ifas.ufl.edu 


\section{RENEWAL INFORMATION}

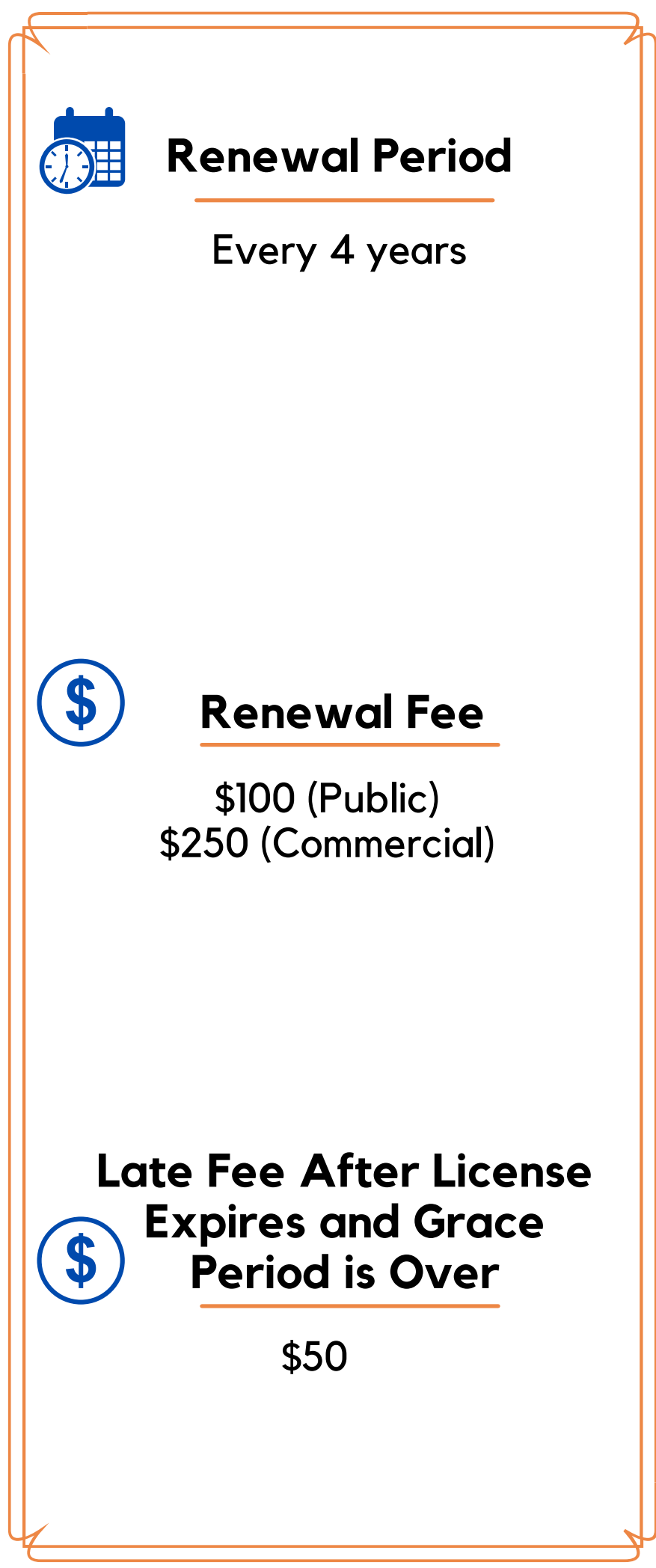

\section{CEU Renewal Requirements}

4 CORE $487 *$

4 Sewer Root

*CORE CEUs are required; however,

no CORE exam is required.

\section{Grace Period After} License Expires

- 365 days to renew

- Late fee charged 60 days after license expiration

\section{(\$) Paying Your Renewal}

You can pay your renewal and upload your documents at https://aesecomm.fdacs.gov 


\section{Chlorine Gas}

- Use of chlorine gas to treat water in residential swimming pools by means of a portable system. Requirement of this license is exempt if using machinery permanently attached to all pools. Commercial license only.

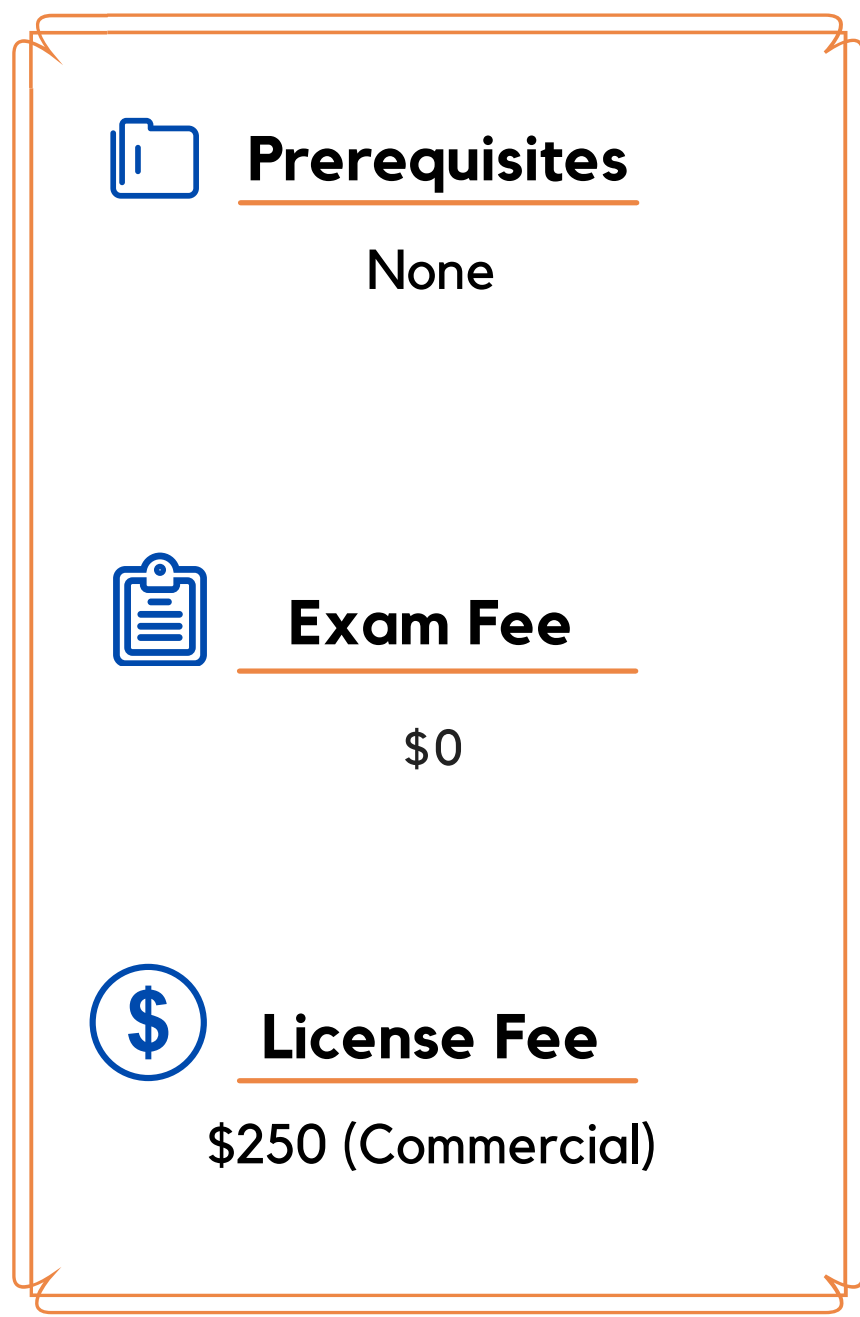

Chlorine Gas Infusion Training Manual

CALL FDACS AT (850)617-7870

\section{渒 Exam Information}

- Chlorine Gas Infusion exam

- 45 questions, multiple-choice

- 2 hours per exam

- Must pass with $70 \%$

Schedule your exam at https://pesticideexam.ifas.ufl.edu 


\section{Chlorine Gas}

\section{RENEWAL INFORMATION}

\section{Renewal Period}

$$
\text { Every } 4 \text { years }
$$

\section{(\$) Renewal Fee \\ $\$ 250$ (Commercial)}

Late Fee After License (\$) Expires and Grace $\$ 50$

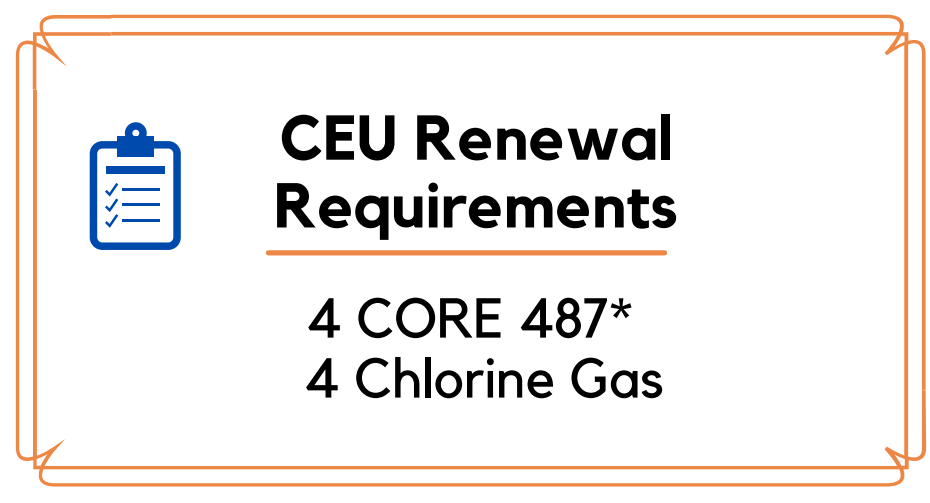

*CORE CEUs are required; however, no CORE exam is required.

\section{Grace Period After} License Expires

- 365 days to renew

- Late fee charged 60 days after license expiration

\section{(\$) Paying Your Renewal}

You can pay your renewal and upload your documents at https://aesecomm.fdacs.gov 


\section{Regulatory Pest Control}

- For state, federal, or other government employees for controlling regulated pests. Public License Only.

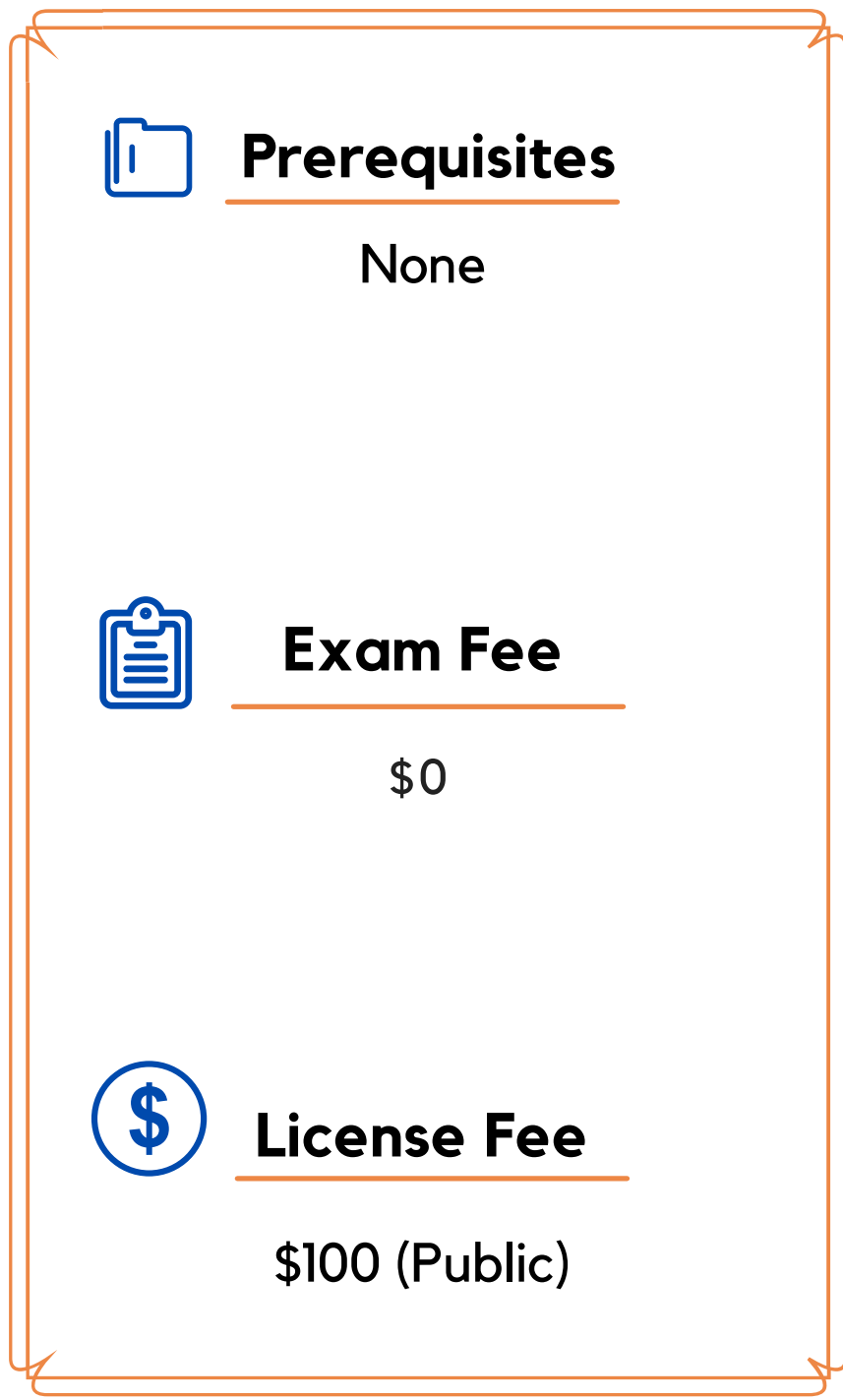

\section{Study Material}

Applying Pesticides Correctly

WWW.IFASBOOKS.COM

SM 1

FDACS Division of Plant Industry

(352)-392-4700 CONDUCTS TRAINING

Additional Study

Material from FDACS

Pesticide Certification

Section

$850-617-7876$

\section{翔 Exam Information}

- Regulatory exam AND General Standards (CORE) Exam

- 50 questions each, multiple-choice

- 2 hours per exam

- Must pass with 70\%

Schedule your exam at https://pesticideexam.ifas.ufl.edu 


\section{Regulatory Pest Control}

RENEWAL INFORMATION

\section{(1) Renewal Period}

Every 4 Years

$\$$

Renewal Fee

$\$ 100$ (Public)

Late Fee After License

(\$) Expires and Grace Period is Over

$\$ 50$

\section{间用}

\section{Grace Period After} License Expires

- 365 days to renew

- Late fee charged 60 days after license expiration

\$) Paying Your Renewal

You can pay your renewal and upload your documents at https://aesecomm.fdacs.gov 


\section{Regulatory Inspection \& Sampling}

- For government employees who must collect regulatory samples of RUP products or conduct inspections that involve handling opened RUP products. License in this category does NOT allow the use of RUP products.

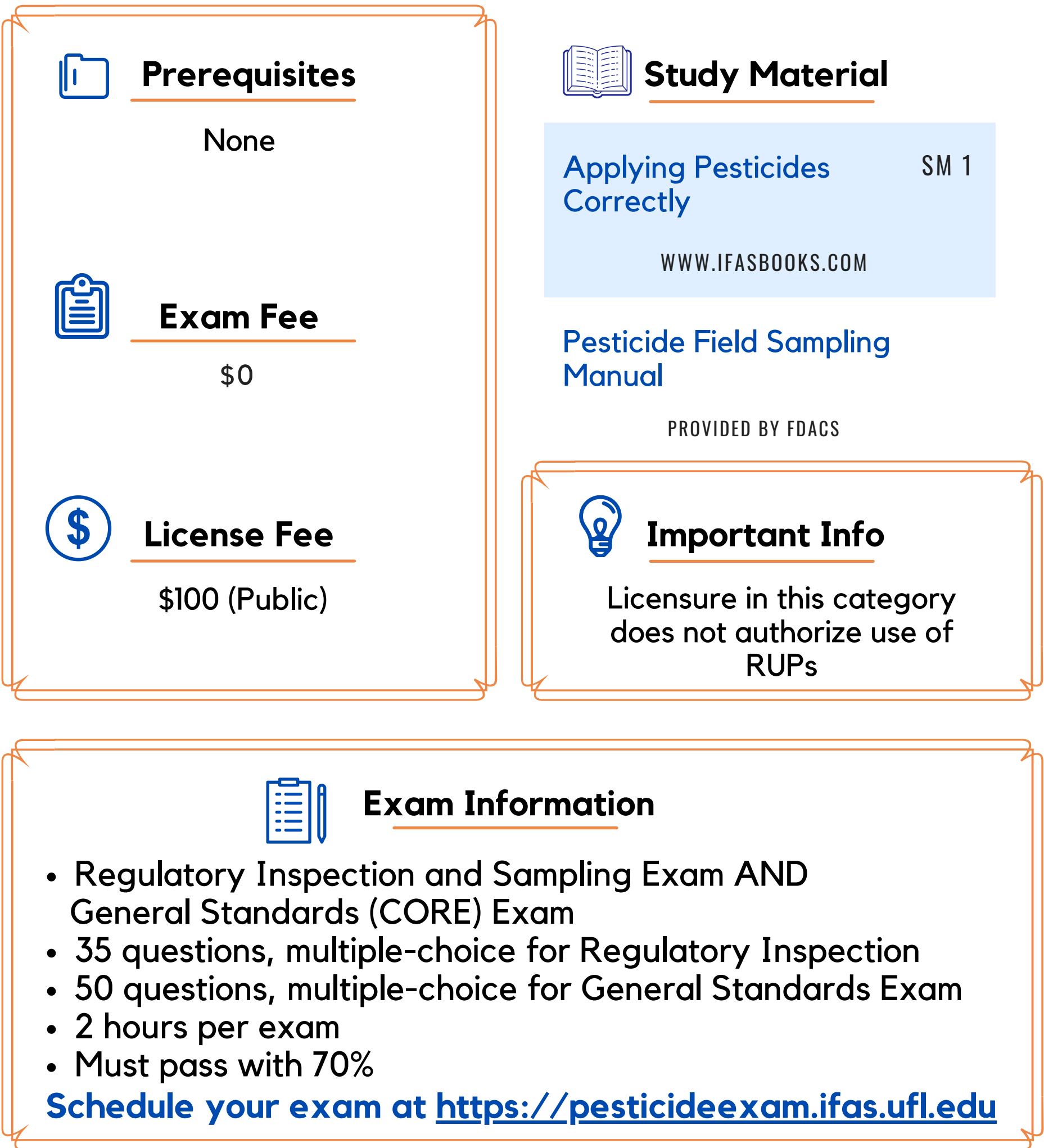




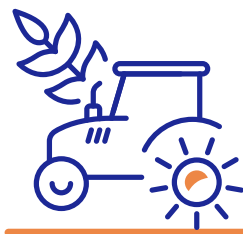

\section{Regulatory \\ Inspection \& Sampling}

RENEWAL INFORMATION

\section{(1) Renewal Period}

Every 4 Years

(\$) Renewal Fee

Public $\$ 100$

Late Fee After License

(\$) Expires and Grace Period is Over $\$ 50$
送 CEU Renewal

4 CORE 487

4 Regulatory Inspection

\section{Grace Period After}

(1) License Expires

- 365 days to renew

- Late fee charged 60 days after license expiration
(\$) Paying Your Renewal

You can pay your renewal and upload your documents at https://aesecomm.fdacs.gov 
(5) - Demonstration and Research

- For those who publicly demonstrate the use of RUP products and those who perform field research using RUP products. NOT a stand-alone category, requires a primary category other than $D \& R$.

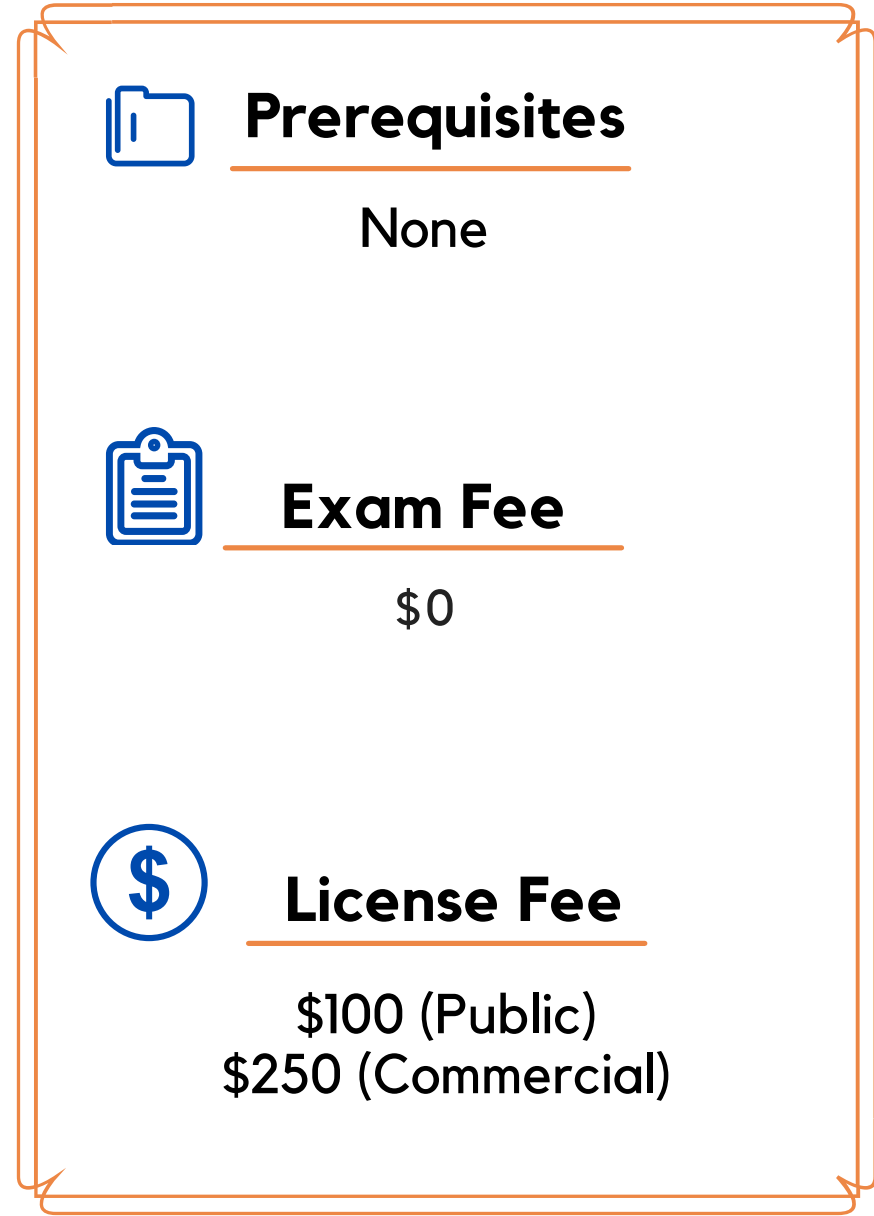

Demonstration and

SM 359

Research Pest Control

WWW.IFASBOOKS.COM

\section{Applying Pesticides $\quad$ SM 1 \\ Correctly}

WWW.IFASBOOKS.COM

\section{Exam Information}

- Demonstration and Research Exam PLUS category Exam AND General Standards (CORE) Exam

- 20 questions, multiple-choice for D\&R exam

- 50 questions each, multiple-choice for category and CORE exam

- 2 hours per exam

- Must pass with $70 \%$

Schedule your exam at https://pesticideexam.ifas.ufl.edu 


\section{2ृ, \\ (5) Demonstration and Research}

\section{RENEWAL INFORMATION}

\section{(1) Renewal Period}

$$
\text { Every } 4 \text { Years }
$$

(\$)

Renewal Fee

$\$ 100$ (Public)

$\$ 250$ (Commercial)

Late Fee After License

(\$) Expires and Grace Period is Over

$\$ 50$
를 CEU Renewal

Requirements

4 CORE 487

$4 \mathrm{D} \& \mathrm{R}$
Grace Period After License Expires

- 365 days to renew

- Late fee charged 60 days after license expiration

\$) Paying Your Renewal

You can pay your renewal and upload your documents at https://aesecomm.fdacs.gov 